\title{
A Circuit for Motor Cortical Modulation of Auditory Cortical Activity
}

\author{
Anders Nelson, ${ }^{\star}$ David M. Schneider, ${ }^{\star}$ Jun Takatoh, Katsuyasu Sakurai, Fan Wang, and Richard Mooney \\ Department of Neurobiology, Duke University Medical Center, Durham, North Carolina 27710
}

Normal hearing depends on the ability to distinguish self-generated sounds from other sounds, and this ability is thought to involve neural circuits that convey copies of motor command signals to various levels of the auditory system. Although such interactions at the cortical level are believed to facilitate auditory comprehension during movements and drive auditory hallucinations in pathological states, the synaptic organization and function of circuitry linking the motor and auditory cortices remain unclear. Here we describe experiments in the mouse that characterize circuitry well suited to transmit motor-related signals to the auditory cortex. Using retrograde viral tracing, we established that neurons in superficial and deep layers of the medial agranular motor cortex (M2) project directly to the auditory cortex and that the axons of some of these deep-layer cells also target brainstem motor regions. Using in vitro whole-cell physiology, optogenetics, and pharmacology, we determined that M2 axons make excitatory synapses in the auditory cortex but exert a primarily suppressive effect on auditory cortical neuron activity mediated in part by feedforward inhibition involving parvalbuminpositive interneurons. Using in vivo intracellular physiology, optogenetics, and sound playback, we also found that directly activating M2 axon terminals in the auditory cortex suppresses spontaneous and stimulus-evoked synaptic activity in auditory cortical neurons and that this effect depends on the relative timing of motor cortical activity and auditory stimulation. These experiments delineate the structural and functional properties of a corticocortical circuit that could enable movement-related suppression of auditory cortical activity.

\section{Introduction}

Auditory sensations reflect a mixture of sounds arising from exafferent sources, such as a nearby conversation, and various reafferent sources, including the auditory feedback generated by vocalization, playing a musical instrument, or walking across a leaf-strewn path. Distinguishing between these two classes of stimuli is a major challenge that the auditory system must overcome to generate accurate auditory percepts and facilitate auditory-guided behaviors. Evidence from a wide variety of sensory systems, including the auditory system, indicates this distinction is facilitated by using corollary discharge from a motor command signal to modulate sensory processing in a movementdependent manner (Holst and Mittelstaedt, 1950; Sperry, 1950; Davis et al., 1973; Bell and Grant, 1989; Sommer and Wurtz, 2002; Poulet and Hedwig, 2006).

Electrophysiological and brain imaging studies in humans and other mammals reveal that a variety of movements modulate auditory processing across many levels of the neuraxis spanning

Received May 28, 2013; revised July 11, 2013; accepted July 30, 2013.

Author contributions: A.N., D.M.S., and R.M. designed research; A.N. and D.M.S. performed research; J.T., K.S., and F.W. contributed unpublished reagents/analytic tools; A.N. and D.M.S. analyzed data; A.N., D.M.S., and R.M. wrote the paper.

This work was supported by National Institutes of Health Grants NS077986 (F.W.), DA028302 (F.W.), and NS079929 (R.M.). We thank Dr. Todd Roberts and members of the Mooney laboratory for discussions and comments on this manuscript and Dr. Kazuto Kobayashi for FuG-B2 plasmid.

${ }^{*}$ A.N. and D.M.S. contributed equally to this work.

The authors declare no competing financial interests.

Correspondence should be addressed to Richard Mooney, Duke University Medical Center, Department of Neurobiology, Box 3209, Durham, NC 27710. E-mail: mooney@neuro.duke.edu.

DOI:10.1523/JNEUROSCI.2275-13.2013

Copyright $\odot 2013$ the authors $\quad 0270-6474 / 13 / 3314342-12 \$ 15.00 / 0$ from the auditory periphery to the auditory cortex (ACtx) (Carmel and Starr, 1963; Schuller, 1979; Curio et al., 2000; Eliades and Wang, 2003, 2008; Phillips-Silver and Trainor, 2005). Although such motor-sensory interactions are widespread in the auditory system, motor cortical modulation of auditory cortical activity is likely to be especially important to vocal communication and auditory-guided motor learning. Specifically, auditory cortical activity is suppressed before and during vocalization in monkeys and humans, and functional studies in humans support a model in which motor cortical activity drives this suppressive effect to facilitate self-monitoring and maintain sensitivity to exafferent stimuli during sound-generated behaviors (Paus et al., 1996; Houde and Jordan, 1998; Eliades and Wang, 2003, 2008). Moreover, dysfunction of cortical corollary discharge machinery is speculated to underlie auditory hallucinations characteristic of psychoses (Ford and Mathalon, 2005; Heinks-Maldonado et al., 2007).

Despite the postulated importance of motor to auditory cortical interactions in normal and disordered audition, the synaptic and circuit mechanisms underlying these interactions remain enigmatic. A likely anatomical substrate for this interaction is the axonal projection certain motor cortical neurons make to the ACtx, a pattern of connectivity observed in mammals ranging from rodents to primates (Alexander et al., 1976; Reep et al., 1987; Hackett et al., 1999; Budinger and Scheich 2009). Although this projection is well documented, less is known about the identity of motor cortical neurons that innervate the ACtx, including their laminar distributions and their anatomical relationship to subcortical structures important to movement. Furthermore, the functional properties of motor cortical synapses in the ACtx, including their sign, their postsynaptic targets, and their capacity to 
Table 1. Summary of the viruses and tracers used in this study

\begin{tabular}{lllll}
\hline Abbreviated name & Full virus or tracer name & Type & Payload or fluorescence & Path of transport \\
\hline RG-LV-Cre & FuG-B2-LV-Cre & Lentivirus & Cre & Retrograde \\
VSV-G-LV-Cre & VSV-G-LV-Cre & Lentivirus & Cre & Anterograde \\
AAV-GFP & AAV.2/1.CAG.FLEX.eGFP.WPRE & AAV & eGFP & Anterograde \\
FLEX-GFP & AAV.2/1.hSyn.ChR2.EYFP.WPRE & AAV & ChR2.EYFP & Anterograde \\
AAV-RFP & AAV.2/1.hSyn.turboRFP & AAV & turboRFP & Anterograde \\
CTB-594 & CTB-Alexa Fluor 594 & Cholera toxin & Alexa Fluor 594 & Retrograde \\
CTB-FITC & CTB-Fluorescein isothiocyanate & Cholera toxin & FITC & Retrograde \\
\hline
\end{tabular}

modulate auditory cortical responsiveness to acoustic stimuli, await clarification. Here we conducted a series of experiments in the mouse using viral and conventional anatomical tracing methods, in vitro whole-cell physiology and pharmacology, in vivo intracellular physiology during sound playback, and selective optogenetic manipulation of motor cortical inputs, to begin to explore how the motor cortex modulates auditory cortical activity. These experiments delineate the anatomical organization and functional properties of a cortical circuit that is well suited to enable movementrelated suppression of auditory cortical activity.

\section{Materials and Methods}

All experimental protocols were approved by Duke University Institutional Animal Care and Use Committee.

Virus generation. The Cre expression vector pseudotyped lentivirus (pLV)-human synapsin I (hSyn)-Cre-woodchuck posttranscriptional regulatory element (WPRE) was based on pFCGW (Dittgen et al., 2004), in which the CAG-EGFP sequence was replaced with human synapsin I promoter-Cre recombinase sequence. For production of the viral vector, the Cre expression plasmid along with two helper plasmids $\Delta 8.9$ and vesicular stomatitis virus glycoprotein (VSV-G) or FuG-B2 (a chimeric envelope protein composed of the extracellular and transmembrane domains of rabies virus glycoprotein (RG) and the cytoplasmic domain of VSV-G; pCAGGS-FuG-B2; a gift from Kazuto Kobayashi, Fukushima Medical University, Fukushima, Japan) (Kato et al., 2011a,b,c) were transfected into HEK293T cells with Lipofectamine2000 (Invitrogen). Viral particles were pelleted by ultracentrifugation at $65,000 \times g$ for $2.5 \mathrm{~h}$ and resuspended in PBS. A compendium of viruses and tracers used in this study is provided in Table 1.

Stereotaxic injections. Ai14 (stock \#007914) (Madisen et al., 2010), parvalbumin (PV)-Cre (stock \#008069), and C57BL/6 (wild-type) mice were obtained from The Jackson Laboratory. For anatomical tracing and in vivo physiology experiments, 2- to 4-month-old animals of either sex were used. For slice physiology experiments, P20-P30 animals of either sex were used. Mice were anesthetized with isoflurane, placed in a stereotaxic holder (Leica), and secured with custom-made zygoma cups. A midline incision was made to reveal the skull, and a small craniotomy was made with a dental drill over the stereotaxically identified region of interest. ACtx was targeted with a pulled glass pipette (Drummond) at a mediolateral $30^{\circ}$ angle from vertical to minimize spread of virus, and $\sim 1$ $\mu \mathrm{l}$ of RG-LV-Cre (Table 1) was pressure injected (Nanoject) over the course of $20 \mathrm{~min}$. For anterograde tracing, the medial agranular motor cortex (M2) of Ai14 mice was injected with $1 \mu \mathrm{l}$ of VSV-G-LV-Cre. Alternatively, M2 of wild-type mice was injected with $150 \mathrm{nl}$ of AAV.2/ 1.hSyn.EGFP.WPRE [adeno-associated virus (AAV)-GFP; University of Pennsylvania Vector Core; Table 1] across three sites and medial geniculate body (MGB) was injected with 400-500 nl of AAV.2/1.hSyn.turboRFP (AAV-RFP; University of Pennsylvania Vector Core; Table 1) at a single site. The periaqueductal gray (PAG) was approached with an anteroposterior $20^{\circ}$ angle from vertical and injected with 150-200 $\mathrm{nl}$ of $1 \%$ cholera toxin $\beta$ subunit conjugated to FITC (CTB-FITC; Sigma; Table 1). For subcortical injections, the tip of the backfilled pipette was loaded with a small volume of saline to prevent unwanted leakage during the descent to the region of interest. For Cre-dependent intersectional viral tracing, $1 \mu \mathrm{l}$ of RG-LV-Cre mixed with $100 \mathrm{nl}$ of $1 \%$ CTB conjugated to Alexa Fluor 594 (CTB-594; Invitrogen; Table 1) was injected into ACtx.
M2 was then injected with 600-800 $\mathrm{nl}$ of AAV.2/1.CAG.FLEX-eGFP.WPRE (AAV-FLEX-GFP; University of Pennsylvania Vector Core; Table 1). For slice physiology and in vivo physiology experiments, M2 was injected with 650-700 $\mathrm{nl}$ of AAV.2/1.hSyn.ChR2.EYFP.WPRE (AAVChR2-YFP; University of Pennsylvania Vector Core; Table 1) at one or two sites. All channelrhodopsin-2 (ChR2) injections were confined to $\mathrm{M} 2$ at locations $1.2-1.8 \mathrm{~mm}$ rostral to bregma. The ventral MGB was then injected with either $200-300 \mathrm{nl}$ of $1 \%$ CTB-594 or $400-500 \mathrm{nl} \mathrm{AAV}$ encoding an XFP. For targeted whole-cell recordings from interneurons, AAV-ChR2 was injected into M2 of the progeny of PV-Cre $\times$ Ai14 mice. For all anatomical tracing and physiology experiments, animals were allowed to survive for $14 \mathrm{~d}$ after injection.

Slice electrophysiology and photostimulation. Mice were first anesthetized with ketamine/xylazine (100 and $10 \mathrm{mg} / \mathrm{kg}$, respectively, i.p.), and transcardially perfused with ice-cold carbogenated artificial CSF (ACSF) containing the following (in $\mathrm{mm}$ ): $119 \mathrm{NaCl}, 2.5 \mathrm{KCl}, 1.30 \mathrm{MgCl}_{2}, 2.5$ $\mathrm{CaCl}_{2}, 1.0 \mathrm{NaH}_{2} \mathrm{PO}_{4}, 26.2 \mathrm{NaHCO}_{3}$, and 11.0 dextrose. The brain was removed, and the rostral pole was glued to the stage of a vibrating microtome (Leica). A $2 \%$ agar block was used to support the ventral surface of the brain, and $300 \mu \mathrm{m}$ coronal slices were cut in a bath of ice-cold ACSF. Slices were incubated for $14 \mathrm{~min}$ in a $34^{\circ} \mathrm{C}$ bath of carbogenated modified ACSF containing the following (in mM): $92 \mathrm{~N}$-methyl-Dglucamine, $2.5 \mathrm{KCl}, 1.2 \mathrm{NaH}_{2} \mathrm{PO}_{4}, 30 \mathrm{NaHCO}_{3}, 20$ HEPES, 25 dextrose, 5 sodium ascorbate, 2 thiourea, 3 sodium pyruvate, $10 \mathrm{MgSO}_{4}$, and 0.5 $\mathrm{CaCl}_{2}$. The slices were then transferred to room temperature ACSF for the duration of the experiment. For voltage-clamp recordings, patch electrodes (2-6 M $\Omega$ ) were filled with internal solution of $5 \mathrm{~mm}$ QX-314, $2 \mathrm{~mm}$ ATP Mg salt, $0.3 \mathrm{~mm}$ GTP Na salt, $10 \mathrm{~mm}$ phosphocreatine, $0.2 \mathrm{~mm}$ EGTA, 2 mм $\mathrm{MgCl}_{2}, 5 \mathrm{~mm} \mathrm{NaCl}, 10 \mathrm{~mm}$ HEPES, $120 \mathrm{~mm}$ cesium methanesulfonate, $0.15 \%$ Neurobiotin, and $0.5 \mathrm{~mm}$ Alexa Fluor 594 cadaverine or $0.1 \mathrm{~mm}$ Alexa Fluor $488 \mathrm{Na}$ salt. For current-clamp recordings, patch pipettes were filled with an internal solution containing $135 \mathrm{~mm}$ K-gluconate, 2 mм $\mathrm{MgCl}_{2}$, 0.5 mм EGTA, 2 mм MgATP, 0.5 mм NaGTP, $10 \mathrm{~mm}$ HEPES, $10 \mathrm{~mm}$ phosphocreatine, $0.15 \%$ Neurobiotin, and $0.5 \mathrm{~mm}$ Alexa Fluor 594 cadaverine or $0.1 \mathrm{~mm}$ Alexa Fluor $488 \mathrm{Na}$ salt. All recordings were made using a Multiclamp 700B amplifier, the output of which was digitized at $10 \mathrm{kHz}$ (Digidata 1440A). Series resistance was always $<30 \mathrm{M} \Omega$ and was compensated up to $90 \%$. Initial in vitro current-clamp recordings were made with sharp intracellular electrodes filled with 5\% Neurobiotin and backfilled with $3 \mathrm{~m}$ KAc, resulting in electrode impedances ranging from 80 to $120 \mathrm{M} \Omega$. To isolate monosynaptic connectivity, recordings were made with room temperature ACSF containing $1 \mu \mathrm{M}$ TTX (Sigma) plus $100 \mu \mathrm{M}$ 4-AP to block action potentials and accentuate light-evoked neurotransmitter release from ChR2-expressing terminals (Petreanu et al., 2009; Cruikshank et al., 2010). To block GABAergic transmission, slices were superfused with ACSF containing $10 \mu \mathrm{M}$ gabazine (Tocris Bioscience) and $50 \mu \mathrm{M}$ CGP-35348 (3-Aminopropyl)(diethoxymethyl)phosphinic acid (Tocris Bioscience). ACtx was identified by both slice morphology and the presence of CTB or AAV-XFP fluorescence from MGB injections. Neurons were targeted using differential interference contrast (DIC) and epifluorescence when appropriate, and neuronal identity was confirmed by morphology after intracellular fill with fluorescent dye. For current-clamp recordings, pyramidal neurons were identified by both morphology after intracellular dye fill and intrinsic membrane properties, including current injection-induced firing pattern and action potential shape. For whole-cell recordings from PV interneurons, tdTomato-expressing neurons were visually targeted, and 
overlay of fluorescence from Alexa Fluor $488 \mathrm{Na}$ salt and native tdTomato was confirmed. ChR2-expressing axon terminals were stimulated by $10 \mathrm{~ms}$ laser pulses (gated by a Uniblitz shutter) of $488 \mathrm{~nm}$ laser light (Prairie Technologies) delivered through a $10 \times$ or $40 \times$ (for interneurons only) objective parfocal with the slice surface and centered over the recording site. Brain slices were histologically processed to visualize Neurobiotin-filled cells using streptavidin Alexa Fluor 488 or 546.

In vivo physiology. One day before physiology, mice were anesthetized with isoflurane $(0.5-3 \%)$, and a metal post was affixed to the skull with dental cement and anchored with two small screws inserted into the skull. On the day of physiology, mice were anesthetized with three intraperitoneal injections of $20 \%$ urethane $(9.5 \mathrm{ml} / \mathrm{kg})$ separated by $30 \mathrm{~min}$, as well as $0.0005 \mathrm{ml}$ atropine $(0.4 \mathrm{mg} / \mathrm{ml})$. Mice were head fixed in a custom stereotaxic holder, and the temporal muscle was resected over the left ACtx. A dental drill was used to thin the skull in two locations over the left ACtx: (1) one thinning on the dorsal surface for electrophysiology and (2) one thinning on the lateral surface for laser stimulation of motor terminals (see Fig. 7). A fiber-optic cable attached to a Shanghai $473 \mathrm{~nm}$ laser was positioned over the lateral thinning perpendicular to the surface of the skull, and the junction between the fiber and the skull was coated with silicon oil to facilitate optical transmission. A small craniotomy was made in the dorsal thinning, the dura was resected, and the brain surface was coated with silicon oil.

Intracellular signals were recorded using glass pipettes pulled with a horizontal puller (Sutter Instruments P-97). Pipette tips were filled with $5 \%$ Neurobiotin and pipettes were backfilled with $3 \mathrm{~m} \mathrm{KAc}$, resulting in electrode impedances ranging from 80 to $120 \mathrm{M} \Omega$. Electrodes were advanced vertically using a hydraulic micromanipulator (SD Instruments) in 5-15 $\mu \mathrm{m}$ steps until the tip of the electrode penetrated a neuron. Electrode signals were amplified with an Axoclamp 2B (Molecular Devices) in bridge mode and acquired with a Power 1401 using Spike 2 (Cambridge Electronic Design). Intracellular signals were recorded if the resting membrane potential of the penetrated neuron was less than -60 $\mathrm{mV}$ and if the membrane potential was modulated by the presentation of at least one tone frequency. Although the electrode path was not perpendicular to the pial surface and therefore not perpendicular to the auditory cortical layers, neurons were recorded at multiple depths and were reliably recorded at depths between 300 and $1000 \mu \mathrm{m}$, suggesting that they were located across multiple cortical layers. All recorded neurons were identified as putative pyramidal neurons based on current-evoked spiking patterns, action potential shape and size, and spontaneous firing rate (McCormick et al., 1985). Additionally, a subset of cells were filled with Neurobiotin and morphologically identified as pyramidal neurons.

Sound stimuli were $80 \mathrm{~ms}$ pure tones $(2,4,8,16,32$, and $81 \mathrm{kHz})$ that were ramped on and off with $10 \mathrm{~ms}$ cosine ramps. For some neurons, a second set of sounds comprising ultrasonic vocalizations from unfamiliar male mice was subsequently presented. Vocalizations had been recorded previously with a condenser microphone (Avisoft Bioacoustics CM16/CMPA) and sampled at $192 \mathrm{kHz}$ (RME Fireface 400). Vocal bouts from two individual mice were presented in their entirety ( $1 \mathrm{~s})$, as were 14 utterances (50-200 ms) that were extracted from the two bouts. Sounds were presented through a free-field electrostatic speaker (Tucker Davis Technologies ES1) located $30 \mathrm{~cm}$ from the contralateral ear. All sounds were presented at $80 \mathrm{~dB}$ SPL. For a particular stimulus set (tones or vocalizations), individual stimuli were pseudorandomly interleaved and were presented 10-30 times each. Included in each stimulus set were laser-alone and blank trials, the latter of which contained neither sound nor laser stimulation. Subsequent stimuli were separated by a silent interval of random duration (range, 550-1100 ms; mean, $770 \mathrm{~ms}$ ). On 50\% of the trials, sound presentation was accompanied by simultaneous laser stimulation. For one-half of the sounds (selected at random), laser stimulation occurred on odd-numbered trials, and for the remaining half of the sounds, laser stimulation occurred on even-numbered trials. For a subset of neurons, the onset asynchrony between sound and laser stimulation [sound onset asynchrony (SOA)] was randomly varied between -100 and $100 \mathrm{~ms}$, in $25 \mathrm{~ms}$ increments, during repeated playback of a single tone that drove a reliable response. Laser stimulation lasted 100 $\mathrm{ms}$, and the stimulation power was constant across all experiments (140 $\mathrm{mW} / \mathrm{mm})$. Sound presentation, laser stimulation, and data acquisition were controlled by custom software written in Spike2 (Cambridge Electronic Design).

Histology. Mice were deeply anesthetized with ketamine/xylazine (100 and $10 \mathrm{mg} / \mathrm{kg}$, respectively, i.p.) and transcardially perfused with PBS, followed by cold $4 \%$ paraformaldehyde. Brains were postfixed overnight in $4 \%$ paraformaldehyde containing $30 \%$ sucrose at $4^{\circ} \mathrm{C}$. Brains were blocked in Optimum Cutting Temperature compound (Tissue-Tek), and $75 \mu \mathrm{M}$ coronal sections were cut using a sliding freezing microtome. For immunostaining, antibodies used were rabbit anti-GFP (1:1000; Abcam), rabbit anti-RFP (1:1000; Clontech), and goat anti-ChAT (1:1000; Millipore AB144P). Secondary antibodies from Jackson ImmunoResearch were used at a concentration of 1:1000. Slices were first rinsed three times in PBS for 5 min, followed by three times in PBS containing $0.3 \%$ Triton X-100 (PBST). Slices were then incubated in PBST containing 10\% Blocking One (Nacalai Tesque) for $1 \mathrm{~h}$ at room temperature. Sections were then incubated with primary antibodies in PBST with $10 \%$ blocking buffer for $3 \mathrm{~d}$ at $4^{\circ} \mathrm{C}$ and then with the appropriate secondary antibody diluted in PBST with $10 \%$ blocking buffer overnight at $4^{\circ} \mathrm{C}$. Sections were washed several times in PBS, incubated in PBS with DAPI for $1 \mathrm{~h}$, rinsed again, and mounted. For anti-GFP immunostaining, sections were incubated in primary antibody overnight at $4^{\circ} \mathrm{C}$ and in secondary antibody for $45 \mathrm{~min}$ at room temperature. For laminar quantification of M2/ lateral agranular motor cortex (M1) neuronal populations in four mice, tissue was imaged with an epifluorescent microscope (Leica), and somata depth relative to the pial surface was quantified by measuring along the axis of the apical dendrite using NIH ImageJ. Cell depth was plotted in $30 \mu \mathrm{m}$ bins. Boundaries between cortical regions were identified using the Franklin and Paxinos (2007) brain atlas. The nonparametric Mann-Whitney $U$ test was used to determine significance. Confocal images were acquired with a Carl Zeiss 710 laser scanning confocal microscope with $10 \times, 20 \times$, or $63 \times$ objectives. Tiled images were stitched during online acquisition (Zen software). Fluorescence intensity across cortical laminae was quantified using NIH ImageJ.

Data analyses. Whole-cell response strength was quantified in Clampfit using peak current amplitude for at least eight trials per stimulus regimen. For analyzing subthreshold responses of in vivo and in vitro current-clamp intracellular recordings, voltage traces were median filtered $(5 \mathrm{~ms})$ to truncate action potentials. The average subthreshold response to repeated presentations of a single stimulus was computed by subtracting the average membrane potential value during the $200 \mathrm{~ms}$ of silence preceding each stimulus onset. Hyperpolarizing and depolarizing areas were measured from average voltage traces during the $300 \mathrm{~ms}$ immediately after stimulus onset. Action potentials were automatically detected based on the magnitude (more than $-30 \mathrm{mV}$ ) and derivative of large depolarizations. Peristimulus time histograms (PSTHs) were computed by binning action potential times in $1 \mathrm{~ms}$ bins, smoothing with a 5 ms Hanning window (25 ms window for data in Fig. $8 D$ ), and averaging across trials and across neurons. The nonparametric Mann-Whitney $U$ test was used to determine significance.

\section{Results}

\section{Motor cortical neurons project to the ACtx}

To begin to characterize motor-related inputs to the ACtx, we combined a novel viral strategy for the retrograde transport of Cre recombinase from axon terminals with a reporter mouse engineered to express tdTomato in neurons in a Cre-dependent manner (Madisen et al., 2010). We injected a retrogradely transported lentivirus pseudotyped with a rabies fusion glycoprotein and VSV-G fusion protein (FuG-B2) (Kato et al., 2011a,b,c; Kinoshita et al., 2012) and encoding Cre (RG-LV-Cre; for a description of all viruses and tracers used in the present study, see Table 1) into primary ACtx of Ai14 ROSA-loxP-STOP-tdTomato transgenic mice (Fig. $1 A, C, n=6$ ). Using this strategy, we were able to achieve robust and stable expression of tdTomato in the cell bodies, dendrites, and axons of neurons in a wide range of brain regions that previous studies have shown provide synaptic input to the ACtx (Fig. $1 B, D$; for a comparison with previous studies, see Table 2). Labeled (tdTo- 

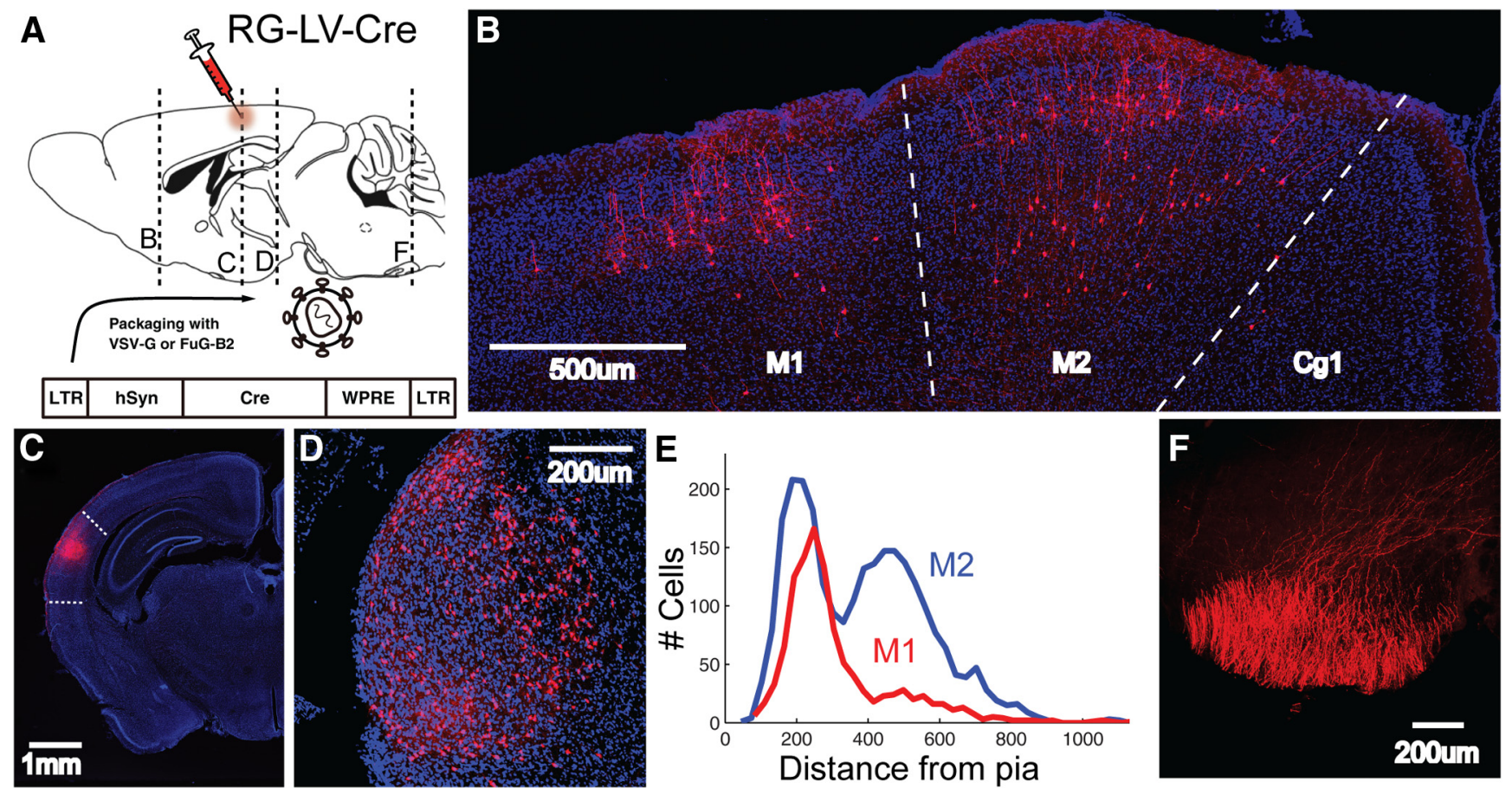

Figure 1. Motor cortical neurons project to the ACtx. $\boldsymbol{A}$, Diagram showing injection of RG-LV-Cre in ACtx of Ai14 mice (top). Dashed lines indicate relative locations of $\boldsymbol{B}-\boldsymbol{D}$ and $\boldsymbol{F}$. Schematic of $\mathrm{RG}-\mathrm{LV}$-Cre (bottom). B, Coronal view of retrograde labeling in motor cortex (red). DAPI is blue. C, Brain slice showing the injection site. ACtx, M1, M2, and cingulate cortex area (Cg1) were demarcated by overlaying the image with the appropriate brain atlas section. $\boldsymbol{D}$, Retrograde labeling in MGB. $\boldsymbol{E}$, Quantification of M2 (blue trace) and M1 (red trace) cell depth relative to pial surface. $\boldsymbol{F}$, Dense axonal labeling in the pyramidal tract. LTR, Long-term repeat.

Table 2. RG-LV-Cre retrograde labeling and consistency with previous studies

\begin{tabular}{|c|c|}
\hline Labeled brain region & Previous studies with similar results \\
\hline Frontal cortex & $\begin{array}{l}\text { Reep et al., 1987; Paperna and Malach, 1991; } \\
\text { Budinger et al., 2008; Lima et al., } 2009\end{array}$ \\
\hline Cingulate cortex & Rouiller et al., 1990; Budinger et al., 2008 \\
\hline Insular cortex & Budinger et al., 2008; Sawatari et al., 2011 \\
\hline Temporal association cortex & Vaudano et al., 1991; Budinger et al., 2008 \\
\hline Somatosensory cortex & Budinger et al., 2006; Lima et al., 2009 \\
\hline Retrosplenial cortex & Budinger et al., 2008 \\
\hline Infralimbic cortex & Budinger et al., 2008 \\
\hline Visual cortex & $\begin{array}{l}\text { Miller and Vogt, 1984; Budinger et al., 2006; } \\
\text { Lima et al., } 2009\end{array}$ \\
\hline Entorhinal cortex & Insausti et al., 1997; Budinger and Scheich, 2009 \\
\hline Perirhinal cortex & $\begin{array}{l}\text { Deacon et al., 1983; Paperna and Malach, 1991; } \\
\text { Budinger and Scheich, } 2009\end{array}$ \\
\hline MGB & $\begin{array}{l}\text { Caviness and Frost, 1980; Cruikshank et al., 2002; } \\
\text { Budinger and Scheich, } 2009\end{array}$ \\
\hline Posterior thalamic nucleus & $\begin{array}{l}\text { Roger and Arnault, 1989; Hofstetter and Ehret, } \\
\text { 1992; Budinger and Scheich, } 2009\end{array}$ \\
\hline Lateral posterior thalamic nucleus & Budinger et al., 2008 \\
\hline Zona incerta & Lin et al., 1990; Budinger and Scheich, 2009 \\
\hline Ventral tegmental area & Bao et al., 2001; Budinger et al., 2008 \\
\hline Hypothalamic area & Budinger et al., 2008 \\
\hline Locus ceruleus & Morrison et al., 1978; Budinger et al., 2008 \\
\hline Nucleus basalis & Metherate and Ashe, 1993; Budinger et al., 2008 \\
\hline Raphe nucleus & Lidov et al., 1980; Budinger et al., 2008 \\
\hline
\end{tabular}

Left column, Brain regions with retrogradely labeled neurons after injection of RG-LV-Cre into ACtx of Ai14 mice (left column); right column, comparison of labeling patterns to similar reports in rodents and other mammals.

mato $^{+}$) cells were found in subcortical regions, including but not limited to ipsilateral MGB of the thalamus, zona incerta, posterior thalamic nucleus, raphe nucleus, ventral tegmental area, as well in frontal, cingulate, and perirhinal cortices.

In the context of the goal of this study of beginning to identify and characterize potential sources of motor-related signals to the ACtx, neurons in the frontal cortex are of special interest, because they have been implicated in the control of a wide range of movements (Neafsey et al., 1986; West and Larson, 1995; Yin, 2009). In fact, large numbers of labeled neurons were detected in M2 and M1 after injections of RG-LV-Cre into the ACtx of Ail4 mice (Fig. 1B). Interestingly, we observed higher numbers of labeled cells in deep layers of M2 compared with M1, a distribution that we quantified by counting the number of labeled cells in each region as a function of distance from the pial surface ( $p=8 e-25, n=4$ animals) (Fig. $1 E$ ). Furthermore, dense bundles of tdTomato ${ }^{+}$fibers were detected in the pyramidal tract (Fig. $1 F$ ), consistent with the idea that some deep-layer cells in $\mathrm{M} 2$ that innervate the $\mathrm{ACtx}\left(\mathrm{M} 2_{\mathrm{ACtx}}\right.$ neurons) also extend axons to the brainstem via the pyramidal tract. Because the ACtx of the mouse receives inputs from large numbers of M2 neurons, including deep-layer cells that could play a direct role in signaling brainstem structures important to motor control, we subsequently restricted our focus to $\mathrm{M} 2_{\mathrm{ACtx}}$ neurons.

\section{M2 neurons project across auditory cortical laminae}

To independently verify that M2 neurons project axons to the ACtx and to better characterize the organization of these projections, we made restricted injections of an anterogradely expressed VSV-G lentivirus encoding Cre (VSV-G-LV-Cre) into the M2 region of Ail 4 mice (Fig. $2 A, B, n=2$ ). This approach resulted in small clusters of tdTomato ${ }^{+}$cell bodies across all layers in M2 and extensive tdTomato ${ }^{+}$fibers throughout the ACtx, as well as in other cortical and subcortical regions (Fig. $2 C-F$ ). After injections of AAV-GFP in M2 and AAV-RFP in the auditory thalamus (MGB) of wild-type mice $(n=2)$, we observed extensive GFP ${ }^{+}$ M2 terminals in the ACtx, which was identified by the presence of $\mathrm{RFP}^{+}$MGB fibers (Fig. 2G,H). Finally, although we found labeled M2 axons in all auditory cortical layers, labeling was more intense in deep and superficial layers compared with intermedi- 

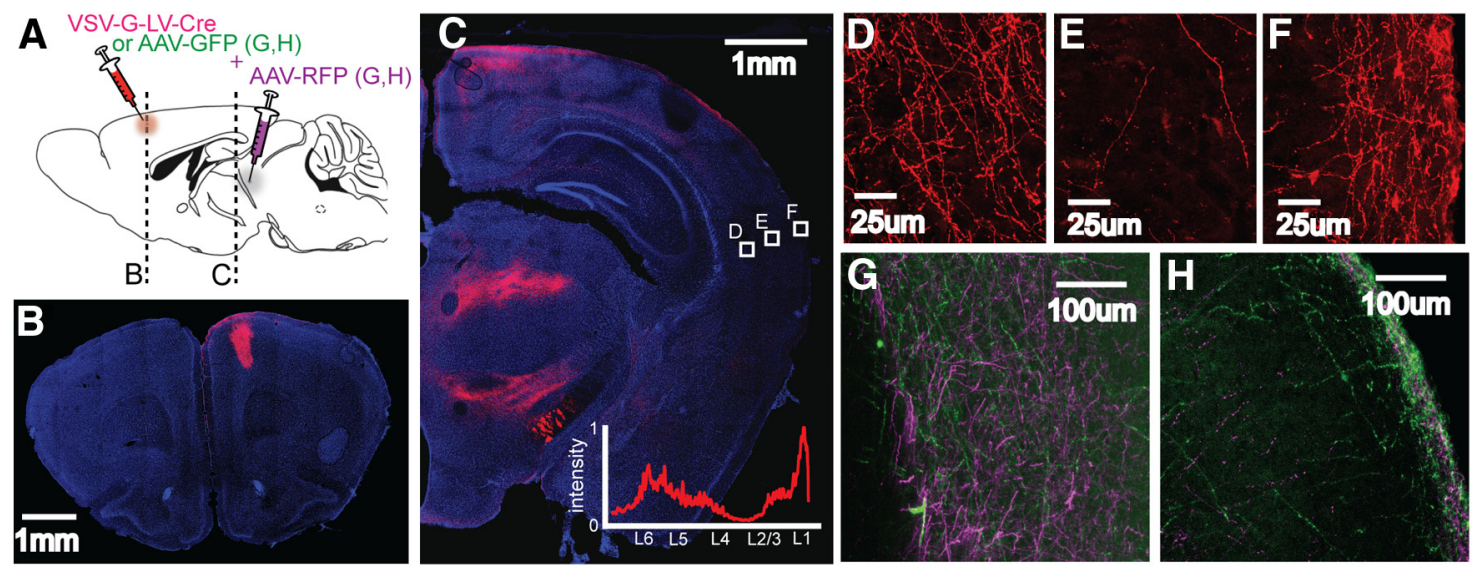

Figure 2. M2 neurons project across auditory cortical laminae. A, Diagram showing injection of VSV-G-LV-Cre in M2 of an Ai14 mouse (B-F) or AAV-GFP in M2 and AAV-RFP in MGB of a wild-type mouse $(\boldsymbol{G}, \boldsymbol{H})$. B, Coronal view of VSV-G-LV-Cre injection site. C, Coronal slice through ACtx. The boxed insets indicate the relative locations of $\boldsymbol{D}-\boldsymbol{F}$. The graphical inset is a quantification of axonal fluorescence across auditory cortical laminae. $\boldsymbol{D}$, High-magnification image of axon labeling in deep layers of ACtx revealed through anti-RFP immunostaining. $\boldsymbol{E}$, High-magnification image of axon labeling in middle layers of ACtx. $\boldsymbol{F}$, High-magnification image of axon labeling in superficial layers of ACtx. $G, M 2$ axons in deep layers of ACtx (green) intermingled with axons from MGB (magenta) after injection of AAV-GFP in M2 and AAV-RFP in MGB. $\boldsymbol{H}$, Axons from M2 and MGB in superficial layers of ACtx.

ate layers (Fig. $2 C-F$, inset in $C$ ). Together, these anatomical studies indicate that $\mathrm{M} 2$ neurons extend axons throughout ACtx, projecting most densely to superficial and deep cortical layers.

\section{A subset of M2 neurons project to both ACtx and subcortical regions}

Motor neurons in deep cortical layers, including layer 5 (L5), are known to innervate a wide range of subcortical structures, including those involved in motor control (Kuypers, 1958; Hardy and Leichnetz, 1981). To determine whether individual M2 neurons that send axons to the ACtx also extend axons to subcortical motor regions, we used an intersectional viral strategy to selectively and extensively label $\mathrm{M} 2_{\mathrm{ACtx}}$ neurons. To this end, we injected AAV-FLEX-GFP into M2 and RG-LV-Cre into the ACtx of wild-type mice, resulting in selective expression of GFP in those $\mathrm{M} 2_{\mathrm{ACtx}}$ neurons infected with both viruses (Fig. $3 A-C, n=$ 3). To confirm that the injection site was located in the ACtx, red fluorescent retrograde tracer (CTB-594) was mixed with the RG$\mathrm{LV}-\mathrm{Cre}$, resulting in red fluorescent retrograde labeling in the MGB (Fig. 3D). Subsequent inspection of fixed tissue revealed $\mathrm{GFP}^{+}$cells bodies in superficial and deep layers of M2 and also revealed $\mathrm{GFP}^{+}$fibers, which we tentatively identified as axons of deep-layer $\mathrm{M} 2_{\mathrm{ACtx}}$ neurons, in the pyramidal tract as well as other subcortical structures. Axon labeling in the ACtx using this approach was comparatively sparse, most likely reflecting the lower probability that the two different viruses would infect a single neuron. Nonetheless, this intersectional approach indicates that $\mathrm{M} 2_{\mathrm{ACtx}}$ neurons extend axons to several cortical and subcortical brain regions, including the thalamus, pons, and the brainstem, and some of these axons terminate in the region of motor neurons (Fig. 3E,F). Notably, we also found rich labeling of axons and putative axon terminals in the PAG, cerebral peduncle, mesencephalic reticular nucleus, and striatum (Fig. $3 G-K$ ).

The PAG is a subcortical region particularly important for vocalization as well as a variety of reproductive, defensive, and maternal behaviors (Kabat, 1936; Oliveras et al., 1974; Storozhuk et al., 1984; Bandler and Shipley, 1994; Jürgens, 1994; Lonstein et al., 1998; Brandão et al., 1999; Sukikara et al., 2006). To gauge the extent to which $\mathrm{M} 2{ }_{\mathrm{ACtx}}$ neurons also project to the PAG, we injected the ACtx of Ail4 mice with RG-LV-Cre and then injected green fluorescent retrograde tracer (CTB-FITC) into the PAG (Fig. $4 A-C, n=2$ ), resulting in extensive green fluorescent retrograde labeling of $\mathrm{M} 2$ neurons providing input to this brainstem structure (Fig. 4D). This approach also yielded doublelabeled neurons in the deep layers of M2, indicating that certain $\mathrm{M} 2_{\mathrm{ACtx}}$ neurons also innervate the PAG (Fig. $4 D-G$ ). Together, these experiments reveal a potential anatomical substrate by which motor cortical neurons that innervate brainstem regions important to a range of social and sexual behaviors also provide monosynaptic input to the ACtx.

\section{M2 interacts with ACtx through feedforward inhibition}

Electrophysiological recordings made in awake, behaving primates have shown that auditory cortical activity is modulated before and during certain movements, such as vocalizations, and that the primary effect of this modulatory signal, which is theorized to originate from motor cortex, is to suppress action potential activity (MüllerPreuss and Ploog, 1981; Eliades and Wang, 2003). To begin to test how $\mathrm{M} 2_{\mathrm{ACtx}}$ axon terminals modulate auditory cortical neuron activity, we injected M2 of juvenile (P20-P30) wild-type mice with AAV-ChR2-YFP (Petreanu et al., 2007) and injected MGB with either red fluorescent retrograde tracer (CTB-594) or an AAV encoding RFP or GFP to delineate the boundaries of ACtx (Fig. 5A). After allowing several weeks to achieve functional expression of $\mathrm{ChR} 2$ in $\mathrm{M}_{\mathrm{ACtx}}$ axon terminals (Fig. $5 \mathrm{~B}$ ), we then cut acute coronal brain slices and made sharp intracellular current-clamp recordings from neurons in ACtx, which was identified in part by the presence of fluorophore-labeled MGB terminals or red fluorescent retrogradely labeled cortical neurons (Fig. 5C,D). Brief (10 ms) pulses of laser light $(\sim 2 \mathrm{~mm}$ in diameter, centered over the recording site) routinely evoked a fast, short latency depolarization, followed by a larger, longer-lasting hyperpolarization (Fig. 5E; $n=15$ pyramidal cells from 3 mice; identified by their directcurrent-evoked membrane potential properties). These observations raise the possibility that motor cortical axons drive monosynaptic excitation and disynaptic feedforward inhibition onto auditory cortical pyramidal cells. To more directly test this idea, we made whole-cell voltage-clamp recordings from auditory cortical pyramidal cells and optogenetically activated $\mathrm{M} 2_{\mathrm{ACtx}}$ inputs at holding potentials that isolated either excitatory or inhibitory synaptic currents $\left(V_{\mathrm{h}}=-70\right.$ and $0 \mathrm{mV}$, respectively). This approach confirmed that optogenetic activation of $\mathrm{M}_{\mathrm{ACtx}}$ axons could elicit both excitatory and inhibitory synaptic currents from auditory cortical pyramidal cells and also revealed that the 

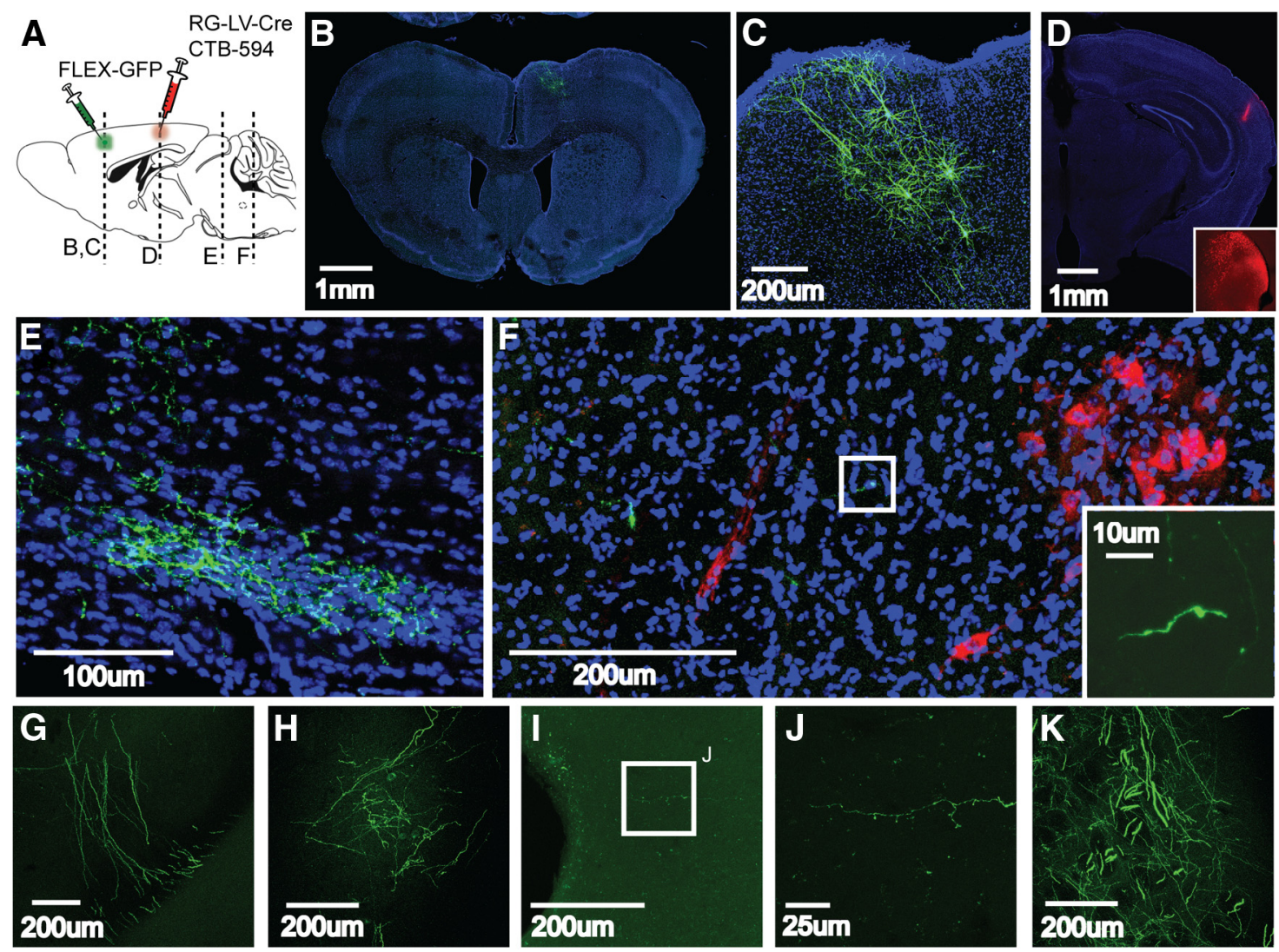

Figure 3. A subset of $M 2$ neurons project to both ACtx and subcortical areas. A, Diagram showing injection of RG-LV-Cre and CTB-594 in ACtx and AAV-FLEX-GFP in M2. B, Low-magnification image of motor cortex. C, GFP labeling in M2. D, RG-LV-Cre and CTB-594 (red) injection site. Inset shows (TB labeling in MGB. E, GFP-labeled axons in the pontine nuclei. $\boldsymbol{F}$, GFP-labeled axons in the brainstem adjacent to ChAT motoneurons (red anti-ChAT immunostaining). Inset shows high-magnification image of axon terminal. Bottom row, GFP-labeled axons in cerebral peduncle (G), mesencephalic reticular nucleus $(\boldsymbol{H}), \operatorname{PAG}(\boldsymbol{I}, \boldsymbol{J})$, and striatum $(\boldsymbol{K})$.
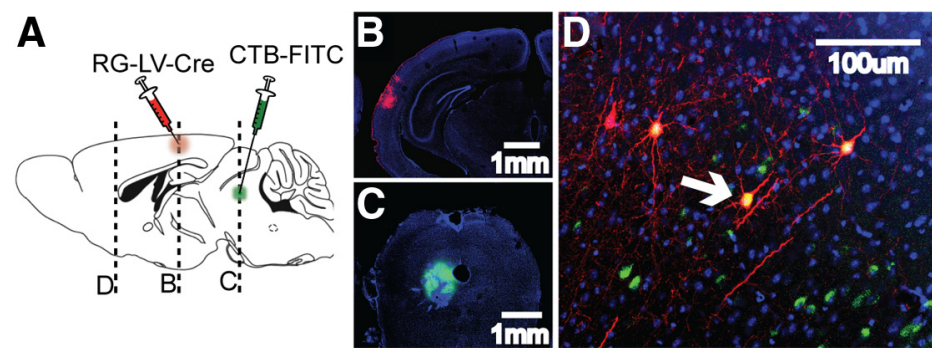

Figure 4. A subset of M2 neurons project to both $A C t x$ and PAG. $A$, Diagram showing injection of RG-LV-Cre in $A C t x$ and CTB-FITC in PAG. B, Coronal view of ACtx injection site. C, Coronal view of PAG injection site. D, Retrograde labeling in M2. Arrow indicates double-labeled cell in $\boldsymbol{E}$ (red channel), $\boldsymbol{F}$ (green channel), and $\mathbf{G}$ (merged).

amplitude of inhibitory current was approximately four times larger than the excitatory current $(n=15$ cells, 2 mice) (Fig. $5 F)$. Inhibitory currents always lagged behind excitatory currents (on average by $3.84 \pm 2.70 \mathrm{~ms}$ at $10 \%$ of maximum amplitude, $n=8$ cells, $p=$ 0.0051 , paired $t$ test) and were reversibly blocked by bath application of $10 \mu \mathrm{M}$ gabazine and $50 \mu \mathrm{M}$ CGP-36348, demonstrating that they were mediated by GABA receptors (Fig. $5 G ; n=8$ cells, 3 mice, $p=$ 0.0018 paired $t$ test; washout was obtained in $n=6$ cells, 3 mice, $p=$ 0.0155 , paired $t$ test).

M2 axons make excitatory synapses on auditory cortical pyramidal cells and interneurons

The compound synaptic potentials we observed in currentclamp recordings suggest that $\mathrm{M} 2_{\mathrm{ACtx}}$ axons make excitatory synapses on both pyramidal neurons and inhibitory interneu-

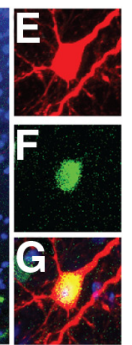

rons within ACtx. To directly test this idea, we made whole-cell recordings from pyramidal neurons as described previously but included $1 \mu \mathrm{M}$ TTX and $100 \mu \mathrm{M}$ 4-AP in the bath ACSF to isolate monosynaptic currents and to facilitate ChR2-evoked neurotransmitter release (Fig. 6A). Using this approach and at holding potentials of $-70 \mathrm{mV}$, we were able to detect fast, inward synaptic currents in $>75 \%$ of auditory cortical neurons (54 of 70 cells from eight mice). The cell bodies of responsive neurons were distributed across all layers of ACtx, consistent with the widespread distribution of $\mathrm{M} 2{ }_{\mathrm{ACtx}}$ axon labeling revealed in our tracing experiments (Fig. $6 B, C$ ). We then made targeted recordings in brain slices from L2/3 and $\mathrm{L}_{5} \mathrm{PV}^{+}$interneurons, which were made to express tdTomato by crossing PV-Cre mice with Ail4 mice (Fig. 6D). In the presence of TTX and 4-AP and at a holding potential of $-70 \mathrm{mV}$, optogenetic stimulation of $\mathrm{M} 2_{\mathrm{ACtx}}$ axons evoked strong inward currents (Fig. $6 E, F ; n=12$ cells, 3 mice). We identified the laminar position of each recorded pyramidal neuron ( $n=47$, identified by visualization of intracellular staining after DIC-targeted recordings) and interneuron [identified by visualization of intracellular staining of either $\mathrm{PV}^{+}$- targeted recordings $(n=12)$ or DIC-targeted recordings $(n=12)]$ and calculated the percentage of neurons re- 
A

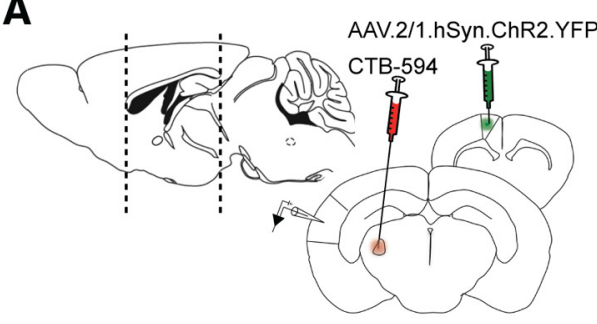

E

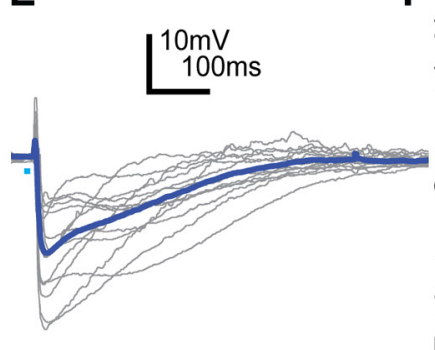

$\mathbf{F}$

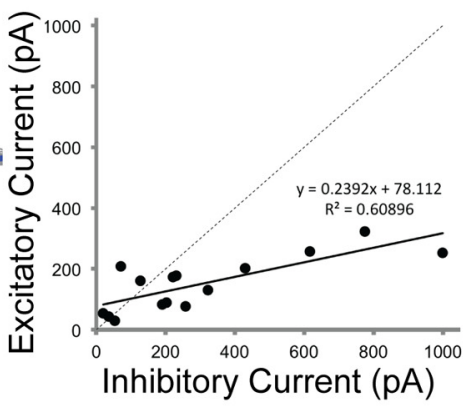

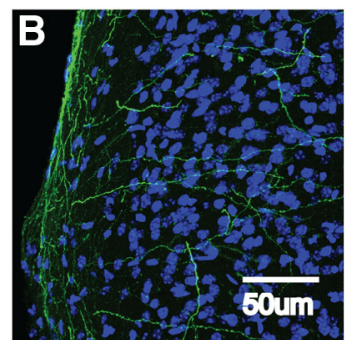
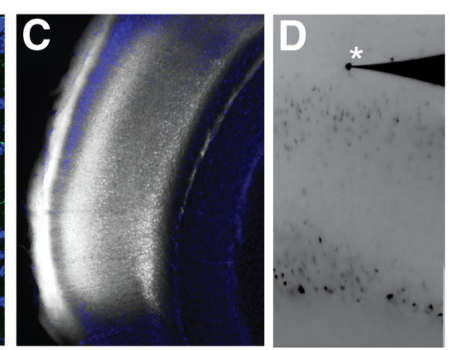

G

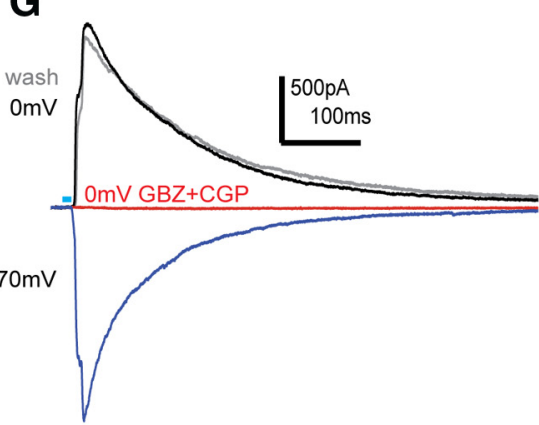

Figure 5. M2 interacts with ACtx through feedforward inhibition. A, Diagram showing injection of AAV-ChR2 in M2 and CTB-594 in MGB. $B$, Anti-GFPlabeling in superficial layers of ACtx showing axons from M2 ChR2 injection. C, Visual identification of ACtx by terminal field labeling from AAV-XFP injection in MGB. D, Visual identification of ACtx by retrograde labeling of MGB-projecting cell bodies after injection of CTB-594 in MGB (all labeled cell bodies other than the recorded neuron). Whole-cell recordings were made under DIC, and recorded neurons were filled with Alexa Fluor 594 during the recording (asterisk). $\boldsymbol{E}$, Average response (blue) of multiple individual neurons (gray, $n=15$ ) to optogenetic stimulation of M2 terminals in current clamp and regular ACSF. $\boldsymbol{F}$, Plot of excitatory versus inhibitory peak amplitude response to optogenetic stimulation of $M 2$ terminals while holding at either $-70 \mathrm{or} 0 \mathrm{mV}$. G, Example responses to optogenetic stimulation showing that inhibitory currents are mediated through GABAergic transmission, which is blocked by bath application of gabazine and CGP-35348.

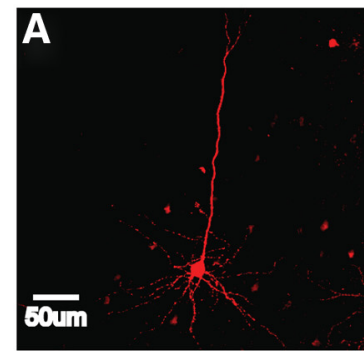

B
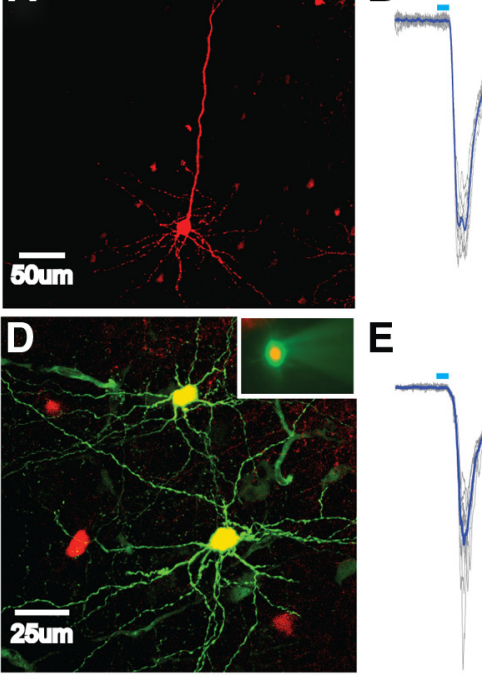

E

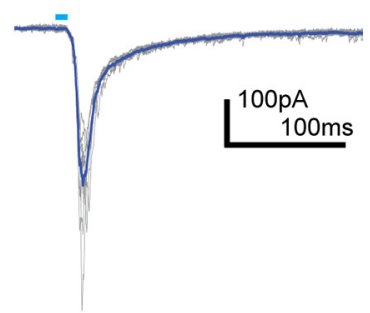

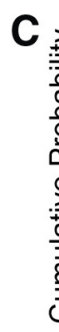
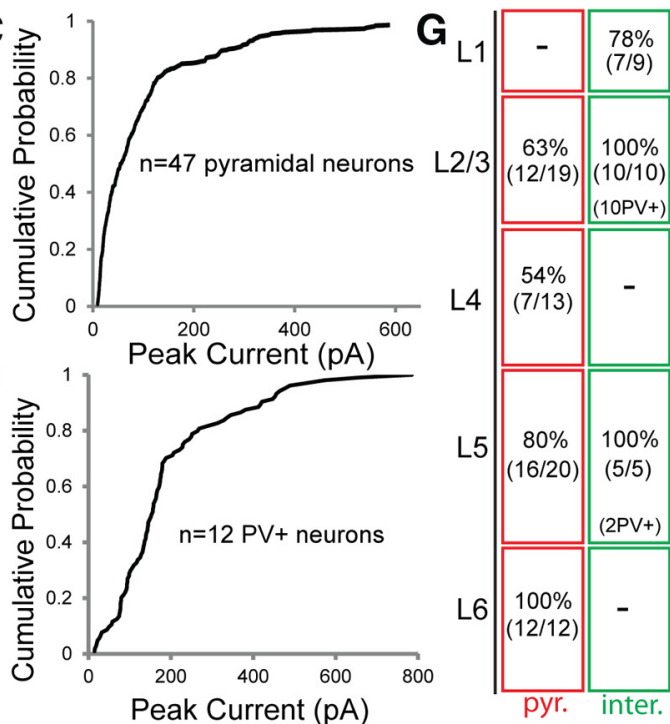

Figure 6. M2 axons make excitatory synapses on auditory cortical pyramidal cells and interneurons. $A$, Morphological reconstruction of an $L 5$ auditory cortical pyramidal neuron after intracellular recording. B, Single-trial (gray) and average (blue) response to optogenetic stimulation of M2 terminals on a pyramidal neuron clamped at $-70 \mathrm{mV}$ and recorded in TTX plus 4-AP. C, Cumulative probability distribution of response amplitude to optogenetic stimulation of M2 terminals from 47 pyramidal ACtx neurons recorded in TTX plus 4-AP. D, Morphological reconstruction of L2 PV interneurons (red) showing two cells filled with biotin and reacted with streptavidin (green). Inset shows fluorescence overlay during whole-cell recording. $E$, Single-trial (gray) and average (blue) response to optogenetic stimulation of $\mathrm{M} 2$ terminals on a PV interneuron clamped at $-70 \mathrm{mV}$ and recorded in TTX plus 4-AP. $F$, Cumulative probability distribution of response amplitude to optogenetic stimulation of M2 terminals from 12 PV interneurons recorded in TTX plus 4-AP. G, Summary of percent of pyramidal neurons (pyr.; red) and interneurons (inter.; green) responsive to optogenetic stimulation, sorted by laminae. Interneuronal recordings here include both fluorescence-targeted PV recordings and DIC-targeted recordings from visually identified interneurons. PV recordings were selectively targeted to $\mathrm{L} 2 / 3$ and $\mathrm{L} 5$ because of the high PV expression pattern in these layers compared with $\mathrm{L} 4$ and $\mathrm{L} 6$.

sponsive to optogenetic stimulation (Fig. 6G). These experiments demonstrate that $\mathrm{M} 2_{\mathrm{ACtx}}$ neurons make excitatory connections on both auditory cortical pyramidal neurons and $\mathrm{PV}^{+}$interneurons, thus defining a circuit capable of modulating auditory cortical activity through direct excitation and feedforward inhibition.
M2 modulates spontaneous activity of ACtx neurons in vivo The tracing and optogenetic circuit mapping experiments we conducted in brain slices suggest that motor cortical inputs to the ACtx could modulate auditory cortical activity, including auditory cortical responses to acoustic stimuli. To begin to address this issue, we injected M2 of adult wild-type mice with AAV- 
A

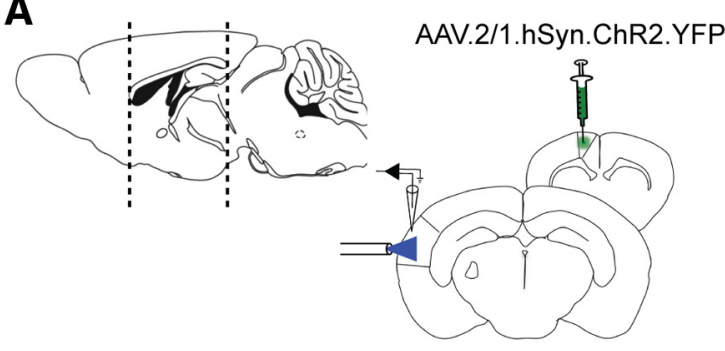

\section{B}

C

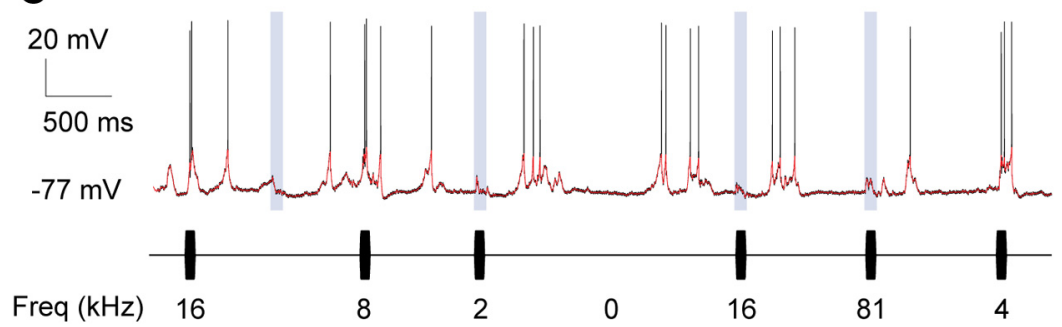

Figure 7. Simultaneous intracellular physiology, sound presentation, and optogenetic stimulation in vivo. A, AAV-ChR2 injections in left M2. Schematic representation of electrode and fiber-optic placement during simultaneous physiology and optogenetic stimulation. B, Morphological reconstruction of an ACtx neuron recorded in vivo. C, Representative subthreshold and spiking response (top) to tone presentation (bottom) and optogenetic stimulation of motor terminals (blue bars). Red line shows medianfiltered membrane potential. Numbers at bottom show tone frequency, where $0 \mathrm{~Hz}$ represents a blank trial used as a control.

A

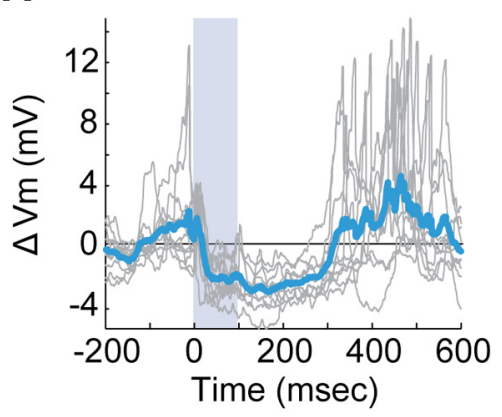

C

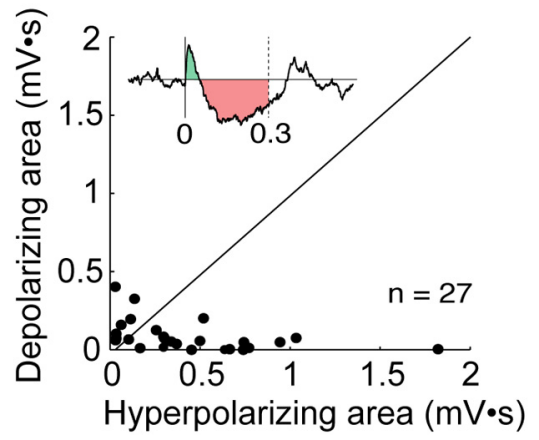

B

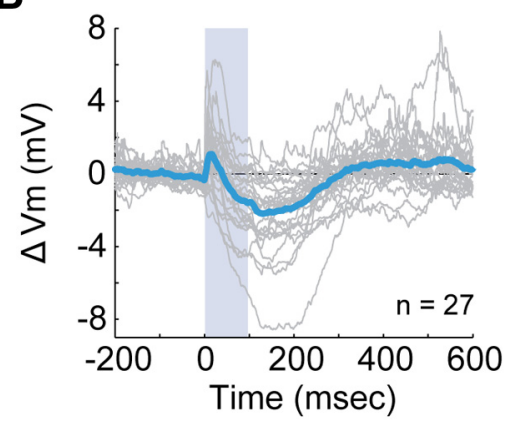

D

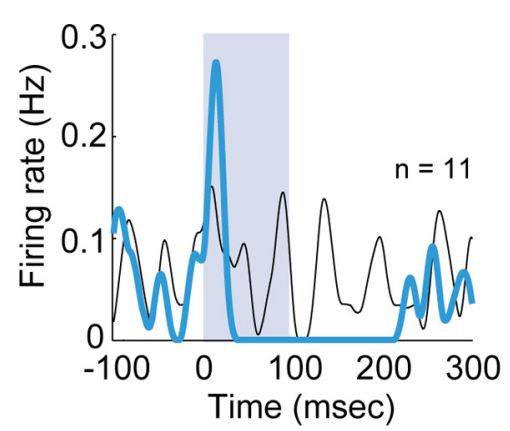

Figure 8. M2 modulates spontaneous activity of ACtx neurons in vivo. $\boldsymbol{A}$, Single trials (gray) and average response (blue) of an individual ACtx neuron to $100 \mathrm{~ms}$ optogenetic stimulation of $M 2$ terminals. $\boldsymbol{B}$, Average response (blue) of multiple individual neurons (gray, $n=27$ ) to optogenetic stimulation of M2 terminals. $C$, Net depolarizing and net hyperpolarizing areas during the $300 \mathrm{~ms}$ after optogenetic stimulation. Inset shows the depolarizing (green) and hyperpolarizing (red) areas for a representative neuron. D, Population PSTHs showing spontaneous firing rate (black) and firing rate after optogenetic stimulation (blue). In $\boldsymbol{A}, \boldsymbol{B}$, and $\boldsymbol{D}$, blue bars indicate duration of optogenetic stimulation.

ChR2-YFP and allowed several weeks to achieve functional expression of ChR2 in $\mathrm{M}_{\mathrm{ACtx}}$ axon terminals in the ACtx (Fig. 7A). We then made in vivo sharp intracellular current-clamp recordings from auditory cortical neurons ( $n=28$ cells, 5 mice) under urethane anesthesia while optogenetically stimulating motor terminals within the ACtx, presenting sounds to the contralateral ear, or both (Fig. $7 B, C)$. In almost all (27 of 28) auditory cortical neurons, we observed significant and reproducible responses to optogenetic stimulation of $\mathrm{M} 2_{\mathrm{ACtx}}$ axon terminals in the absence of acoustic stimuli (Fig. 8A). For most neurons, laser illumination over the recording site caused a small depolarization followed by a large and sustained hyperpolarization that outlasted illumination by $\sim 200 \mathrm{~ms}$, remarkably similar to the compound synaptic potentials observed after optogenetic stimulation of M2 terminals in auditory cortical brain slices (Fig. 8B, compare with Fig. $5 E)$. To better quantify the synaptic effects of laser illumination, we independently calculated the depolarizing and hyperpolarizing areas during the $300 \mathrm{~ms}$ immediately after the onset of laser stimulation (Fig. $8 C$, inset). We found that the hyperpolarizing effect was approximately five times greater than the depolarizing effect $(-0.422 \pm 0.408$ $\mathrm{mV} \cdot s$, hyperpolarizing; $0.083 \pm 0.098 \mathrm{mV} \cdot \mathrm{s}$, depolarizing) (Fig. $8 C$ ), in close agreement with the ratio of inhibitory/excitatory currents measured in brain slices. To determine whether optogenetic stimulation of M2 terminals influenced the spontaneous action potential activity of auditory cortical neurons, we calculated the population-averaged PSTH in response to laser trials as well as blank trials. In the minority of auditory cortical neurons that generated action potentials spontaneously ( 11 of 27 cells), we observed a brief $(\sim 25 \mathrm{~ms})$ increase in action potential rates at the onset of laser stimulation, followed by a strong suppression of action potential activity that lasted $\sim 200 \mathrm{~ms}$ (Fig. $8 D$ ). During this $200 \mathrm{~ms}$ window, spontaneous firing was completely suppressed by laser stimulation (1.71 \pm 0.99 spikes/s, blank trials; $0 \pm 0$ spikes/s, laser trials; $p=0.016$ ).

\section{M2 modulates sound-evoked activity of} auditory cortical neurons in vivo

We next determined the degree to which stimulation of M2 terminals modulated sound-evoked activity in the ACtx. We presented brief tones $(80 \mathrm{~ms}, 80 \mathrm{~dB} S \mathrm{SP})$ at a range of frequencies spanning the audible spectra of mice $(2,4,8,16,32$, and 81 $\mathrm{kHz}$ ), and, on $50 \%$ of trials, we paired tone presentation with laser stimulation of M2 terminals in the ACtx. In response to tones, individual neurons showed reliable and reproducible membrane potential depolarizations (100 \pm 107 ms; Fig. 9A). During simultaneous sound and laser stimu- 

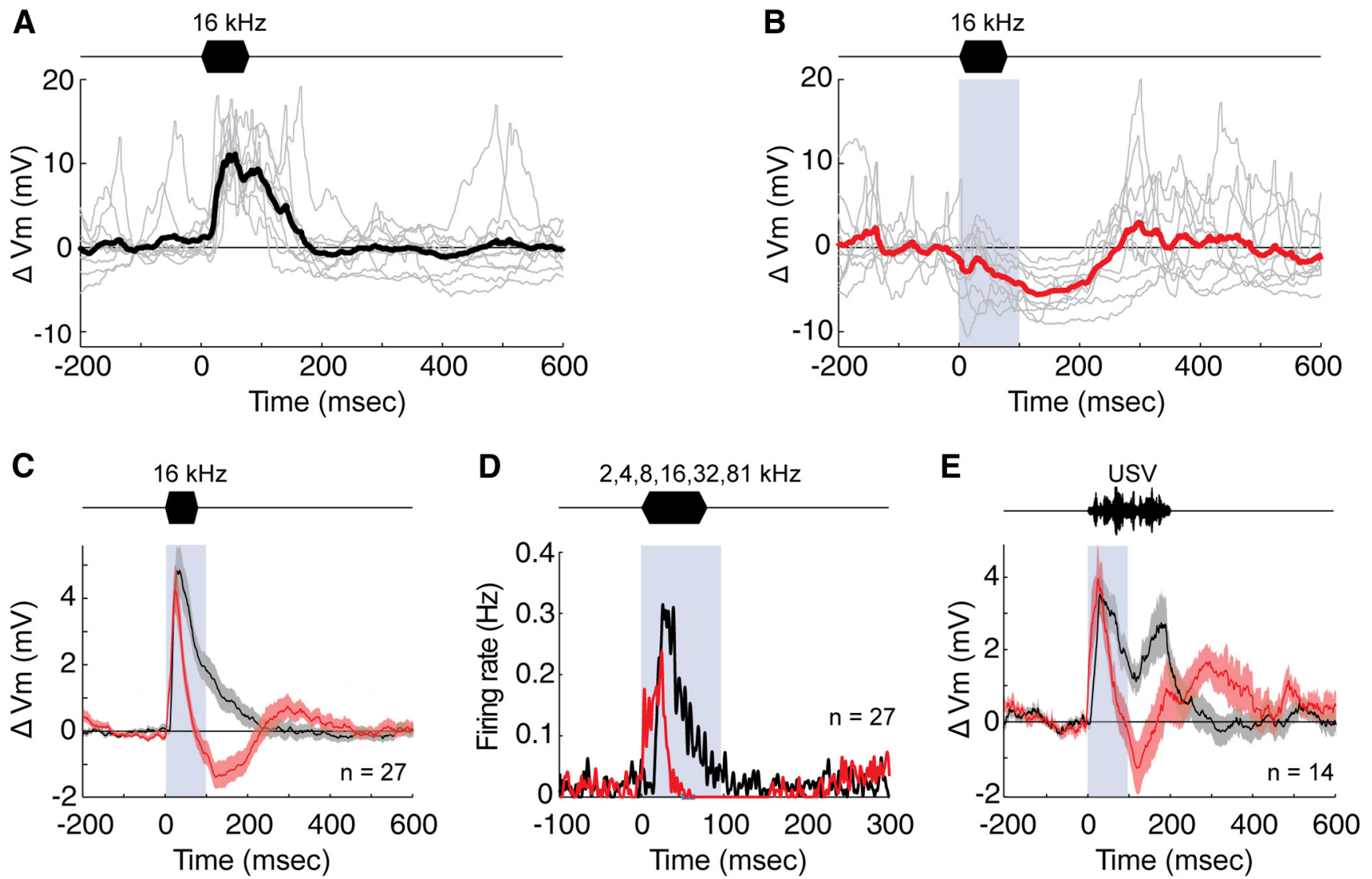

Figure 9. M2 suppresses sound-evoked responses in vivo. $\boldsymbol{A}$, Single trials (gray) and average response (black) of an individual ACtx neuron to 80 ms tone. $\boldsymbol{B}$, Single trials (gray) and average response (red) of the same neuron to simultaneous tone and optogenetic stimulation. C, Population average response to tone (black) and to simultaneous tone and optogenetic stimulation (red). Shaded area shows SEM. D, Population PSTH during tone presentation (black) and simultaneous tone and optogenetic stimulation (red), averaged across all tone frequencies. $\boldsymbol{E}$, Population average response to an ultrasonic vocalization (USV; black) and in response to simultaneous vocalization and optogenetic stimulation (red). Shaded area shows SEM.

lation, depolarizations were significantly shorter in duration than during sound presentation alone $(60 \pm 118 \mathrm{~ms} ; p=$ 0.0002 ), and, for some neurons (7 of 27), concurrent laser stimulation was sufficient to completely abolish membrane potential responses to a subset of tones (Fig. 9B). On average, optogenetic stimulation of M2 terminals truncated the depolarizing phase of auditory responses within $100 \mathrm{~ms}$ of stimulus onset and significantly hyperpolarized neurons for the following $100 \mathrm{~ms}$ (Fig. 9C). The voltage area measured during the $300 \mathrm{~ms}$ after stimulus onset was significantly smaller during simultaneous sound and laser stimulation $(-23 \pm 468 \mathrm{mV} / \mathrm{s})$ compared with sound stimulation alone $(267 \pm 361 \mathrm{mV} / \mathrm{s} ; p=$ $6 e-9)$. Laser stimulation of M2 terminals also led to a decrease in sound-evoked spiking during the $300 \mathrm{~ms}$ after stimulus onset $(1.10 \pm 2.16 \mathrm{spikes} / \mathrm{s}$, sound; $0.59 \pm 1.56 \mathrm{spikes} / \mathrm{s}$, sound and laser; $p=0.0002$ ), including a complete absence of spikes in the $150 \mathrm{~ms}$ window beginning $100 \mathrm{~ms}$ after laser onset (Fig. $9 D)$. Although auditory cortical neurons as a group had a range of best frequencies, laser stimulation suppressed subthreshold responses consistently independent of stimulus frequency. To determine whether M2 terminal stimulation also suppressed responses to spectrotemporally complex sounds, for a subset of neurons $(n=14$ neurons recorded from 2 male and 2 female virgin mice), we presented mouse ultrasonic vocalizations with and without simultaneous laser stimulation. Auditory neurons were reliably depolarized by vocalizations, and, as with tone stimulation, vocalization-driven responses were significantly suppressed by simultaneous laser stimulation $(248 \pm 356 \mathrm{mV} / \mathrm{s}$, sound; $39 \pm 596 \mathrm{mV} / \mathrm{s}$, sound and laser; $p=0.003$ ) (Fig. $9 E$ ).

If $\mathrm{M} 2{ }_{\mathrm{ACtx}}$ axons normally function to convey a premotor signal to the ACtx, these signals should presumably precede the arrival of reafferent auditory information (Crapse and Sommer, 2008). Therefore, we systematically varied the onset asynchrony between sound stimulation and laser stimulation (SOA) to determine how M2 inputs modulate sound-evoked activity at various time lags that are likely to encompass a natural range of premotor latencies exhibited by M2 neurons (Huang et al., 1988; Brecht et al., 2004). Optogenetically stimulating M2 $\mathrm{ACtx}$ axon terminals in the ACtx before sound presentation was often sufficient to completely abolish auditory-evoked depolarizations recorded from auditory cortical neurons, whereas reversing this sequence resulted in no significant suppressive effect (Fig. 10A). Across neurons ( $n=7,2$ mice), the suppressive effect of M2 terminal stimulation was strongest when it preceded sound stimulation by $0-100 \mathrm{~ms}$ (Fig. 10B), in agreement with a model in which the more rapid propagation of motor-related activity to the ACtx acts to suppress longer latency reafferent auditory information.

\section{Discussion}

Here we used viral and transgenic anatomical tracing techniques to identify and characterize a corticocortical circuit involving neurons in mouse M2 that directly innervate the ACtx. Through intersectional viral labeling techniques, we found that a subset of $\mathrm{M} 2_{\mathrm{ACtx}}$ neurons also send projections to subcortical regions involved in ex- 


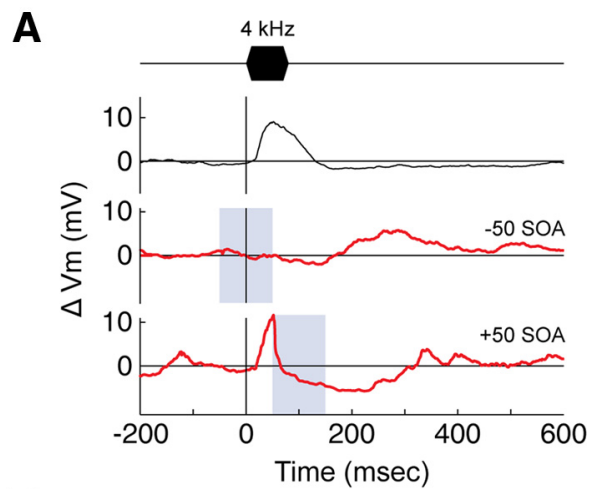

B

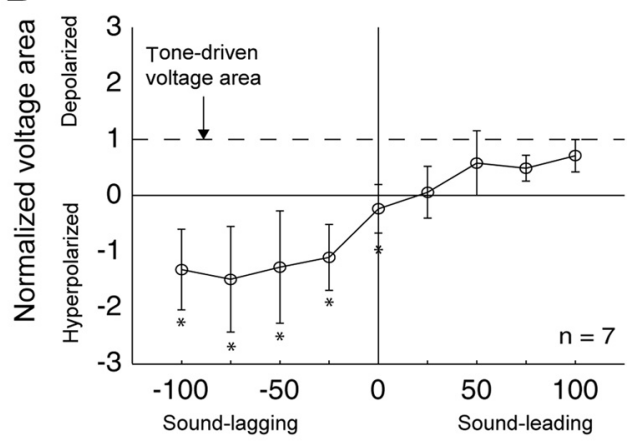

Stimulus onset asynchrony (msec)

Figure 10. M2-mediated suppression is maximized when $M 2$ input precedes auditory input. $\boldsymbol{A}$, Response of an individual ACtx neuron to a tone (top), to a tone preceded by optogenetic stimulation (middle) and to a tone followed by optogenetic stimulation (bottom). $\boldsymbol{B}$, Normalized voltage area in response to a tone that is preceded (negative SOA) or followed (positive $\mathrm{SOA}$ ) by laser stimulation. Normalized voltage areas $<1$ are smaller than the response to tone alone, and values $<0$ are hyperpolarized relative to baseline. Error bars show SEM. Asterisks indicate suppression relative to tone presented alone $(p<0.05)$.

ecuting movements. By combining whole-cell slice physiology and optogenetic circuit mapping techniques, we showed that motor cortical axons make excitatory synapses in the ACtx but exert a primarily suppressive effect on auditory cortical neurons mediated in part by feedforward inhibition involving $\mathrm{PV}^{+}$interneurons. Last, we combined in vivo intracellular physiology with optogenetic stimulation to show that activating M2 axon terminals in the ACtx suppresses spontaneous and sound-evoked subthreshold and action potential activity of individual auditory cortical neurons and that the magnitude of this suppressive effect was maximized when motor terminal stimulation preceded sound stimulation. Together, these findings delineate a circuit mechanism by which the motor cortex can modulate auditory cortical processing and thus potentially influence auditory perception and behavior.

Our strategy to retrogradely label motor cortical inputs to the ACtx is based on the injection of a lentiviral vector pseudotyped with the fusion protein between the extracellular domain of RG and the transmembrane/intracellular domain of VSV-G (FuG$\mathrm{B} 2)$, and encoding Cre recombinase ( $\mathrm{RG}-\mathrm{LV}-\mathrm{Cre}$ ), into the brain of a mouse in which neurons are engineered to express tdTomato in a Cre-dependent manner. Similar pseudotyped LV vectors have been shown to enhance retrograde transport of viral content, a strategy now extensively characterized in both rodents and monkeys (Kato et al., 2011a,b,c; Kinoshita et al., 2012). In addition to the enhanced retrograde transport characteristic of rabies viruses, this pseudotyping strategy benefits from stable expression characteristic of lentiviruses. As documented here, these technical advantages, combined with robust Cre-dependent re- porter expression characteristic of the Ai14 transgenic mouse line, permit the ready visualization of neuronal cell bodies, dendrites, and extensive axonal processes.

The cortical and subcortical brain regions retrogradely labeled in our anatomical experiments using RG-LV-Cre are similar to those described in previous anatomical studies that have mapped auditory cortical afferents using conventional and viral retrograde tracing methods (Budinger and Scheich, 2009; Table 2). One novel observation revealed with the RG-LV-Cre method used here was the much higher proportion of auditory cortical input derived from deep-layer neurons in M2 compared with mostly superficial layer cells in M1. Because some of these deeplayer M2 neurons also project to subcortical and brainstem regions, they are well situated to directly convey a copy of descending motor information to the ACtx. Consistent with this model, RG-LV-Cre injections into the ACtx of Ail4 mice resulted in a high density of axon labeling in the pyramidal tract (Fig. $1 F$ ), suggesting that some frontal cortical neurons that extend axons into the brainstem and spinal cord also extend axon collaterals to the ACtx. Furthermore, an intersectional viral strategy confirmed that individual deep-layer M2 neurons extend axons to both the ACtx and one or more subcortical brain regions, including the PAG, a region important to vocalization as well as reproductive behaviors (Bandler and Shipley, 1994; Jürgens, 1994; Lonstein et al., 1998). Finally, anterograde viral-mediated tracing independently confirmed the projection from M2 to the ACtx and allowed us to determine that M2 axons extend across all laminae of the ACtx.

The widespread distribution of M2 axon terminals across different layers of the ACtx, as well as the broad distribution of auditory cortical projecting neurons across many layers of M2, raise the possibility that M2 can exert a variety of modulatory, facilitatory, and suppressive effects on auditory cortical activity. Using in vitro whole-cell physiology, optogenetics, and pharmacology, we demonstrated that $\mathrm{M} 2{ }_{\mathrm{ACtx}}$ axon terminals exert a predominantly suppressive effect on auditory cortical activity through feedforward inhibition, an effect mediated in part through excitatory synapses that $\mathrm{M} 2$ axons make onto $\mathrm{PV}^{+}$inhibitory interneurons. Although to our knowledge this is the first description of a motor-related circuit that can modulate auditory cortical processing, it bears some similarities to other corticocortical circuitry and subcortical inputs to the ACtx. For instance, several studies have examined the synaptic connectivity between the vibrissal motor cortex (vM1) and vibrissal somatosensory cortex (vS1), in which there appears to be a particularly strong and coordinated interaction (Izraeli and Porter, 1995; Hoffer et al., 2005). In L1 of somatosensory cortex, terminals from motor cortex encode a variety of movements in a manner capable of dynamically updating the sensory representation of whisker position (Petreanu et al., 2012). Additionally, meticulous dissection of the microcircuit interaction between $\mathrm{vM} 1$ and $\mathrm{vS} 1$ has revealed a projection distributed across S1 laminae, including L2/3 and L5 (Mao et al., 2011), similar to the widespread distribution of M2 synapses we observed in the ACtx. Within ACtx, footshockdriven activation of nucleus basalis is known to facilitate toneevoked responses in L2/3 pyramidal cells through a mechanism that involves L1 interneuron-mediated disinhibition (Letzkus et al., 2011). Although we also observed that $\mathrm{M} 2_{\mathrm{ACtx}}$ axons make dense projections in L1 of ACtx, the net effect of activating $\mathrm{M} 2{ }_{\mathrm{ACtx}}$ terminals in the ACtx in brain slices was to suppress rather than facilitate the activity of auditory cortical pyramidal cells, including those in L2/3. A limitation of the current study is that our optogenetic stimulation methods presumably activated 
axons from both deep and superficial layer $\mathrm{M} 2_{\mathrm{ACtx}}$ neurons, and these axon types may display different patterns of connectivity. In this light, a goal of future experiments will be to determine whether axons arising from different M2 cell layers activate different local circuits in the ACtx and exert distinct effects on auditory cortical processing, auditory perception, and auditoryguided behaviors.

By combining intracellular physiology with optogenetic stimulation and sound playback in vivo, we extended the finding that $\mathrm{M} 2_{\mathrm{ACtx}}$ neurons and their axons exert a suppressive effect on the ACtx to the intact brain. More specifically, we showed that optogenetic stimulation of $\mathrm{M} 2_{\mathrm{ACtx}}$ terminals in the ACtx can suppress the subthreshold and action potential responses of auditory cortical neurons to simple and complex sounds and that motor terminal activation was maximally suppressive when it preceded auditory stimulus presentation by $\sim 100 \mathrm{~ms}$. A variety of studies in humans, nonhuman primates, and songbirds have revealed that auditory cortical activity can be suppressed up to several hundred milliseconds before and also during self-generated vocalizations (Curio et al., 2000; Eliades and Wang, 2003; Keller and Hahnloser, 2009). The timing of the M2-driven suppression that we observed in the ACtx of the anesthetized mouse is in close agreement with movement-related suppression observed in the ACtx of behaving animals, thus providing a plausible circuit mechanism by which motor-related signals emanating from M2 could influence auditory cortical processing to facilitate vocal communication and other auditory-guided behaviors.

Our findings support a model in which signals arising from the motor cortex can suppress auditory cortical responses to ascending signals from the MGB, while providing a corticocortical circuit suitable for the integration of motor-related signals with ascending auditory information. Future experiments are necessary to reveal how the activity of $\mathrm{M} 2_{\mathrm{ACtx}}$ relates to natural behaviors, such as vocalizing, grooming, and walking, and how $\mathrm{M} 2$ input influences auditory processing during natural, self-generated movements. Moreover, although the current study focused on dissecting and characterizing the circuit connecting M2 to the ACtx, our findings and previous studies indicate that the ACtx receives input from a variety of cortical and subcortical regions, all of which could potentially influence auditory cortical activity. Understanding how, and in what contexts, auditory cortical activity is modulated by M2 neurons as well as neurons in these other brain regions will be critical for understanding higher-order aspects of auditory function. A crucial step in this regard will be to transfer the techniques described here to behaving animals to understand how movement, attention, arousal, and task engagement influence auditory processing important to perception, vocal communication, social cognition, and various forms of auditory-guided behavior and learning.

The goals of this study were to provide an initial description of the organization and function of motor cortical synapses in the ACtx. The motor-to-auditory circuit we describe is well suited to convey motor-related information to the ACtx during self-generated movements. In humans, circuits that convey such corollary discharge signals in the ACtx are thought to facilitate auditory comprehension during vocalization and as part of a predictive mechanism to detect vocal errors during speech learning (Crapse and Sommer, 2008; Hickok et al., 2011). Finally, dysfunction of corollary discharge circuits conveying motor signals to the ACtx could potentially generate phantom percepts, such as the complex, voice-like hallucinations associated with schizophrenia and other neuropathologies (Ford and Mathalon, 2005). Our findings provide a wiring diagram for studying motor-auditory interactions in the cortex, which will serve as a platform for future studies that seek to investigate the behavioral and perceptual ramifications of motor influences on normal and disordered audition.

\section{References}

Alexander GE, Newman JD, Symmes D (1976) Convergence of prefrontal and acoustic inputs upon neurons in the superior temporal gyrus of the awake squirrel monkey. Brain Res 116:334-338. CrossRef Medline

Bandler R, Shipley MT (1994) Columnar organization in the midbrain periaqueductal gray: modules for emotional expression? Trends Neurosci 17: 379-389. CrossRef Medline

Bao S, Chan VT, Merzenich MM (2001) Cortical remodelling induced by activity of ventral tegmental dopamine neurons. Nature 412:79-83. CrossRef Medline

Bell CC, Grant K (1989) Corollary discharge inhibition and preservation of temporal information in a sensory nucleus of mormyrid electric fish. J Neurosci 9:1029-1044. Medline

Brandão ML, Anseloni VZ, Pandóssio JE, De Araújo JE, Castilho VM (1999) Neurochemical mechanisms of the defensive behavior in the dorsal midbrain. Neurosci Biobehav Rev 23:863-875. CrossRef Medline

Brecht M, Schneider M, Sakmann B, Margrie TW (2004) Whisker movements evoked by stimulation of single pyramidal cells in rat motor cortex. Nature 427:704-710. CrossRef Medline

Budinger E, Scheich H (2009) Anatomical connections suitable for the direct processing of neuronal information of different modalities via the rodent primary auditory cortex. Hear Res 258:16-27. CrossRef Medline

Budinger E, Heil P, Hess A, Scheich H (2006) Multisensory processing via early cortical stages: connections of the primary auditory cortical field with other sensory systems. Neuroscience 143:1065-1083. CrossRef Medline

Budinger E, Laszcz A, Lison H, Scheich H, Ohl FW (2008) Non-sensory cortical and subcortical connections of the primary auditory cortex in Mongolian gerbils: bottom-up and top-down processing of neuronal information via field AI. Brain Res 1220:2-32. CrossRef Medline

Carmel PW, Starr A (1963) Acoustic and nonacoustic factors modifying middle-ear muscle activity in waking cats. J Neurophysiol 26:598-616. Medline

Caviness VS Jr, Frost DO (1980) Tangential organization of thalamic projections to the neocortex in the mouse. J Comp Neurol 194:335-367. CrossRef Medline

Crapse TB, Sommer MA (2008) Corollary discharge across the animal kingdom. Nat Rev Neurosci 9:587-600. CrossRef Medline

Cruikshank SJ, Rose HJ, Metherate R (2002) Auditory thalamocortical synaptic transmission in vitro. J Neurophysiol 87:361-384. Medline

Cruikshank SJ, Urabe H, Nurmikko AV, Connors BW (2010) Pathwayspecific feedforward circuits between thalamus and neocortex revealed by selective optical stimulation of axons. Neuron 65:230-245. CrossRef Medline

Curio G, Neuloh G, Numminen J, Jousmäki V, Hari R (2000) Speaking modifies voice-evoked activity in the human auditory cortex. Hum Brain Mapp 9:183-191. CrossRef Medline

Davis WJ, Siegler MV, Mpitoses (1973) Distributed neuronal oscillators and efference copy in the feeding system of Pleurobranchaea. J Neurophysiol 36:258-274. Medline

Deacon TW, Eichenbaum H, Rosenberg P, Eckmann KW (1983) Afferent connections of the perirhinal cortex in the rat. J Comp Neurol 220:168-190. CrossRef Medline

Dittgen T, Nimmerjahn A, Komai S, Licznerski P, Waters J, Margrie TW, Helmchen F, Denk W, Brecht M, Osten P (2004) Lentivirus-based genetic manipulations of cortical neurons and their optical and electrophysiological monitoring in vivo. Proc Natl Acad Sci U S A 101:18206-18211. CrossRef Medline

Eliades SJ, Wang X (2003) Sensory-motor interaction in the primate auditory cortex during self-initiated vocalizations. J Neurophysiol 89:21942207. Medline

Eliades SJ, Wang X (2008) Neural substrates of vocalization feedback monitoring in primate auditory cortex. Nature 453:1102-1106. CrossRef Medline

Ford JM, Mathalon DH (2005) Corollary discharge dysfunction in schizophrenia: can it explain auditory hallucinations? Int J Psychophysiol 58: 179-189. CrossRef Medline

Franklin KB, Paxinos G (2007) The mouse brain in stereotaxic coordinates. San Diego: Academic. 
Hackett TA, Stepniewska I, Kaas JH (1999) Prefrontal connections of the parabelt auditory cortex in macaque monkeys. Brain Res 817:45-58. CrossRef Medline

Hardy SG, Leichnetz GR (1981) Frontal cortical projections to the periaqueductal gray in the rat: a retrograde and orthograde horseradish peroxidase study. Neurosci Lett 23:13-17. CrossRef Medline

Heinks-Maldonado TH, Mathalon DH, Houde JF, Gray M, Faustman WO, Ford JM (2007) Relationship of imprecise corollary discharge in schizophrenia to auditory hallucinations. Arch Gen Psychiatry 64:286-296. CrossRef Medline

Hickok G, Houde J, Rong F (2011) Sensorimotor integration in speech processing: computational basis and neural organization. Neuron 69: 407-422. CrossRef Medline

Hoffer ZS, Arantes HB, Roth RL, Alloway KD (2005) Functional circuits mediating sensorimotor integration: quantitative comparisons of projections from rodent barrel cortex to primary motor cortex, neostriatum, superior colliculus, and the pons. J Comp Neurol 488:82-100. CrossRef Medline

Hofstetter KM, Ehret G (1992) The auditory cortex of the mouse: connections of the ultrasonic field. J Comp Neurol 323:370-386. CrossRef Medline

Holst E, Mittelstaedt H (1950) The reafference principle. Naturwissenschaften 37:464-467. CrossRef

Houde JF, Jordan MI (1998) Sensorimotor adaptation in speech production. Science 279:1213-1216. CrossRef Medline

Huang CS, Sirisko, MA, Hiraba H, Murray GM, Sessle BJ (1988) Organization of the primate face motor cortex as revealed by intracortical microstimulation and electrophysiological identification of afferent inputs and corticobulbar projections. J Neurophysiol 59:796-818. Medline

Insausti R, Herrero MT, Witter MP (1997) Entorhinal cortex of the rat: cytoarchitectonic subdivisions and the origin and distribution of cortical efferents. Hippocampus 7:146-183. CrossRef Medline

Izraeli R, Porter LL (1995) Vibrissal motor cortex in the rat: connections with the barrel field. Exp Brain Res 104:41-54. CrossRef Medline

Jürgens U (1994) The role of the periaqueductal grey in vocal behaviour. Behav Brain Res 62:107-117. CrossRef Medline

Kabat H (1936) Electrical stimulation of points in the forebrain and midbrain: the resultant alterations in respiration. J Comp Neurol 64:187-208. CrossRef

Kato S, Kobayashi K, Inoue K, Kuramochi M, Okada T, Yaginuma H, Morimoto K, Shimada T, Takada M, Kobayashi K (2011a) A lentiviral strategy for highly efficient retrograde gene transfer by pseudotyping with fusion envelope glycoprotein. Hum Gene Ther 22:197-206. CrossRef Medline

Kato S, Kuramochi M, Kobayashi K, Fukabori R, Okada K, Uchigashima M, Watanabe M, Tsutsui Y, Kobayashi K (2011b) Selective neural pathway targeting reveals key roles of thalamostriatal projection in the control of visual discrimination. J Neurosci 31:17169-17179. CrossRef Medline

Kato S, Kuramochi M, Takasumi K, Kobayashi K, Inoue K, Takahara D, Hitoshi S, Ikenaka K, Shimada T, Takada M, Kobayashi K (2011c) Neuron-specific gene transfer through retrograde transport of lentiviral vector pseudotyped with a novel type of fusion envelope glycoprotein. Hum Gene Ther 22:1511-1523. CrossRef Medline

Keller GB, Hahnloser RH (2009) Neural processing of auditory feedback during vocal practice in a songbird. Nature 457:187-190. CrossRef Medline

Kinoshita M, Matsui R, Kato S, Hasegawa T, Kasahara H, Isa K, Watakabe A, Yamamori T, Nishimura Y, Alstermark B, Watanabe D, Kobayashi K, Isa $\mathrm{T}$ (2012) Genetic dissection of the circuit for hand dexterity in primates. Nature 487:235-238. CrossRef Medline

Kuypers HG (1958) Corticobular connexions to the pons and lower brainstem in man: an anatomical study. Brain 81:364-388. CrossRef Medline

Letzkus JJ, Wolff SB, Meyer EM, Tovote P, Courtin J, Herry C, Lüthi A (2011) A disinhibitory microcircuit for associative fear learning in the auditory cortex. Nature 480:331-335. CrossRef Medline

Lidov HG, Grzanna R, Molliver ME (1980) The serotonin innervation of the cerebral cortex in the rat-an immunohistochemical analysis. Neuroscience 5:207-227. CrossRef Medline

Lima SQ, Hromádka T, Znamenskiy P, Zador AM (2009) PINP: a new method of tagging neuronal populations for identification during in vivo electrophysiological recording. PLoS One 4:e6099. CrossRef Medline

Lin CS, Nicolelis MA, Schneider JS, Chapin JK (1990) A major direct GABAe- rgic pathway from zona incerta to neocortex. Science 248:1553-1556. CrossRef Medline

Lonstein JS, Simmons DA, Stern JM (1998) Functions of the caudal periaqueductal gray in lactating rats: kyphosis, lordosis, maternal aggression, and fearfulness. Behav Neurosci 112:1502-1518. CrossRef Medline

Madisen L, Zwingman TA, Sunkin SM, Oh SW, Zariwala HA, Gu H, Ng LL, Palmiter RD, Hawrylycz MJ, Jones AR, Lein ES, Zeng H (2010) A robust and high-throughput Cre reporting and characterization system for the whole mouse brain. Nat Neurosci 13:133-140. CrossRef Medline

Mao T, Kusefoglu D, Hooks BM, Huber D, Petreanu L, Svoboda K (2011) Long-range neuronal circuits underlying the interaction between sensory and motor cortex. Neuron 72:111-123. CrossRef Medline

McCormick DA, Connors BW, Lighthall JW, Prince DA (1985) Comparative electrophysiology of pyramidal and sparsely spiny stellate neurons of the neocortex. J Neurophysiol 54:782-806. Medline

Metherate R, Ashe JH (1993) Nucleus basalis stimulation facilitates thalamocortical synaptic transmission in the rat auditory cortex. Synapse 14:132-143. CrossRef Medline

Miller MW, Vogt BA (1984) Direct connections of rat visual cortex with sensory, motor, and association cortices. J Comp Neurol 226:184-202. CrossRef Medline

Morrison JH, Grzanna R, Molliver ME, Coyle JT (1978) The distribution and orientation of noradrenergic fibers in neocortex of the rat: an immunofluorescence study. J Comp Neurol 181:17-39. CrossRef Medline

Müller-Preuss P, Ploog D (1981) Inhibition of auditory cortical neurons during phonation. Brain Res 215:61-76. CrossRef Medline

Neafsey EJ, Bold EL, Haas G, Hurley-Gius KM, Quirk G, Sievert CF, Terreberry RR (1986) The organization of the rat motor cortex: a microstimulation mapping study. Brain Res 396:77-96. CrossRef Medline

Oliveras JL, Woda A, Guilbaud G, Besson JM (1974) Inhibition of the jaw opening reflex by electrical stimulation of the periaqueductal gray matter in the awake, unrestrained cat. Brain Res 72:328-331. CrossRef Medline

Paperna T, Malach R (1991) Patterns of sensory intermodality relationships in the cerebral cortex of the rat. J Comp Neurol 308:432-456. CrossRef Medline

Paus T, Perry DW, Zatorre RJ, Worsley KJ, Evans AC (1996) Modulation of cerebral blood flow in the human auditory cortex during speech: role of motor-to-sensory discharges. Eur J Neurosci 8:2236-2246. CrossRef Medline

Petreanu L, Huber D, Sobczyk A, Svoboda K (2007) Channelrhodopsin-2assisted circuit mapping of long-range callosal projections. Nat Neurosci 10:663-668. CrossRef Medline

Petreanu L, Mao T, Sternson SM, Svoboda K (2009) The subcellular organization of neocortical excitatory connections. Nature 457:1142-1145. CrossRef Medline

Petreanu L, Gutnisky DA, Huber D, Xu NL, O’Connor DH, Tian L, Looger L, Svoboda K (2012) Activity in motor-sensory projections reveals distributed coding in somatosensation. Nature 489:299-303. CrossRef Medline

Phillips-Silver J, Trainor LJ (2005) Feeling the beat: movement influences infant rhythm perception. Science 308:1430. CrossRef Medline

Poulet JF, Hedwig B (2006) The cellular basis of a corollary discharge. Science 311:518-522. CrossRef Medline

Reep RL, Corwin JV, Hashimoto A, Watson RT (1987) Efferent connections of the rostral portion of medial agranular cortex in rats. Brain Res Bull 19:203-221. CrossRef Medline

Roger M, Arnault P (1989) Anatomical study of the connections of the primary auditory area in the rat. J Comp Neurol 287:339-356. CrossRef Medline

Rouiller EM, Innocenti GM, De Ribaupierre F (1990) Interconnections of the auditory cortical fields of the cat with the cingulate and parahippocampal cortices. Exp Brain Res 80:501-511. Medline

Sawatari H, Tanaka Y, Takemoto M, Nishimura M, Hasegawa K, Saitoh K, Song WJ (2011) Identification and characterization of an insular auditory field in mice. Eur J Neurosci 34:1944-1952. CrossRef Medline

Schuller G (1979) Vocalization influences auditory processing in collicular neurons of the CF-FM-bat, Rhinolophus ferrumequinum. J Comp Physiol 132:39-46. CrossRef

Sommer MA, Wurtz RH (2002) A pathway in primate brain for internal monitoring of movements. Science 296:1480-1482. CrossRef Medline

Sperry RW (1950) Neural basis of the spontaneous optokinetic response produced by visual inversion. J Comp Physiol Psychol 43:482-489. CrossRef Medline 
Storozhuk VM, Ivanova SF, Tal'nov AN (1984) Role of the midbrain periaqueductal gray matter in conditioned reflexes. Neurophysiology 16 $3: 320-332$.

Sukikara MH, Mota-Ortiz SR, Baldo MV, Felício LF, Canteras NS (2006) A role for the periaqueductal gray in switching adaptive behavioral responses. J Neurosci 26:2583-2589. CrossRef Medline

Vaudano E, Legg CR, Glickstein M (1991) Afferent and efferent connections of temporal association cortex in the rat: a horseradish peroxidase study. Eur J Neurosci 3:317-330. CrossRef Medline

West RA, Larson CR (1995) Neurons of the anterior mesial cortex related to faciovocal activity in the awake monkey. J Neurophysiol 74:1856-1869. Medline

Yin HH (2009) The role of the murine motor cortex in action duration and order. Front Integr Neurosci 3:23. CrossRef Medline 